\title{
Quantum Dot Nanomedicine Formulations Dramatically Improve Pharmacological Properties and Alter Uptake Pathways of Metformin and Nicotinamide Mononucleotide in Aging Mice
}

Nicholas J. Hunt, Glen P. Lockwood, Sun W. S. Kang, Lara J. Westwood, Christina Limantoro, Wojciech Chrzanowski, Peter A. G. McCourt, Zdenka Kuncic, David G. Le Couteur, and Victoria C. Cogger*

Cite This: ACS Nano 2021, 15, 4710-4727

Read Online

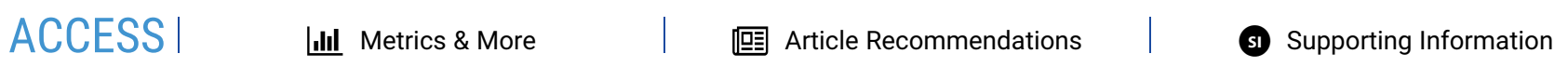

ABSTRACT: Orally administered $\mathrm{Ag}_{2} \mathrm{~S}$ quantum dots (QDs) rapidly cross the small intestine and are taken up by the liver. Metformin and nicotinamide mononucleotide (NMN) target metabolic and aging processes within the liver. This study examined the pharmacology and toxicology of QD-based nanomedicines as carriers of metformin and NMN in young and old mice, determining if their therapeutic potency and reduced effects associated with aging could be improved. Pharmacokinetic studies demonstrated that QD-conjugated metformin and NMN have greater bioavailability, with selective accumulation in the liver following oral administration compared to unconjugated formulations. Pharmacodynamic data showed that the QD-conjugated medicines had increased physiological, metabolic, and cellular potency compared to unconjugated formulations $(25 \times$ metformin; $100 \times \mathrm{NMN})$ and highlighted a shift in the peak induction of, and greater metabolic response to, glucose tolerance testing. Two weeks of treatment with low-dose QD-NMN $(0.8 \mathrm{mg} / \mathrm{kg} /$ day) improved glucose tolerance tests in young (3 months) mice, whereas old (18 and $24 \mathrm{months}) \mathrm{mice}$ demonstrated improved fasting and fed insulin levels and insulin resistance. High-dose unconjugated $\mathrm{NMN}(80 \mathrm{mg} / \mathrm{kg} / \mathrm{day})$ demonstrated improvements in young mice but not in old mice. After 100 days of $\mathrm{QD}(320 \mu \mathrm{g} / \mathrm{kg} / \mathrm{day})$ treatment, there was no evidence of cellular necrosis, fibrosis, inflammation, or accumulation. $\mathrm{Ag}_{2} \mathrm{~S} \mathrm{QD}$ nanomedicines improved the pharmacokinetic and pharmacodynamic properties of metformin and NMN by increasing their therapeutic potency, bypassing classical cellular uptake pathways, and demonstrated efficacy when drug alone was ineffective in aging mice.

KEYWORDS: pharmaceutical, drug development, nanocrystals, liver, pharmacokinetics, pharmacodynamics

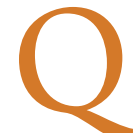

uantum dots (QDs) are multifunctional nanocrystals with bioimaging, detection, and drug delivery applications. ${ }^{1,2}$ The ideal nanomaterial transporters should have minimal effects on biological systems and be removed and/or eliminated after drug delivery. ${ }^{3,4}$ One limitation of QDs is that they can accumulate in the liver or be phagocytosed by immune cells, leading to prolonged exposure and potential toxicity. ${ }^{5}$ Recent progress toward reducing toxicity includes specific biomimicry coating and the use of nontoxic materials such as silver. ${ }^{6}$

The avid uptake and clearance of nanomedicines by the liver is an obstacle for systemic therapies and therapies targeting other organs, but this is an advantage for therapies targeting the liver itself. ${ }^{7,8}$ Such pharmacotherapies include those targeting a range of age-related and metabolic conditions. ${ }^{9}$ We previously developed a QD nanocarrier that enhances oral bioavailability

Received: November 5, 2020

Accepted: February 9, 2021

Published: February 24, 2021 
A. Schematic of attachment of metformin and nicotinamide mononucleotide to $\mathrm{Ag}_{2} \mathrm{~S}$ quantum dots using EDC/NHS chemical coupling

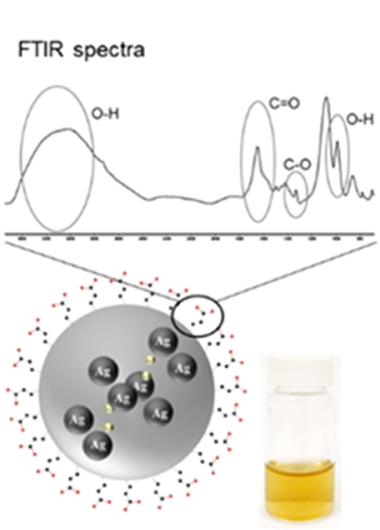

$\mathrm{Ag}_{2} \mathrm{~S}$ QD capped with $\mathrm{COOH}$
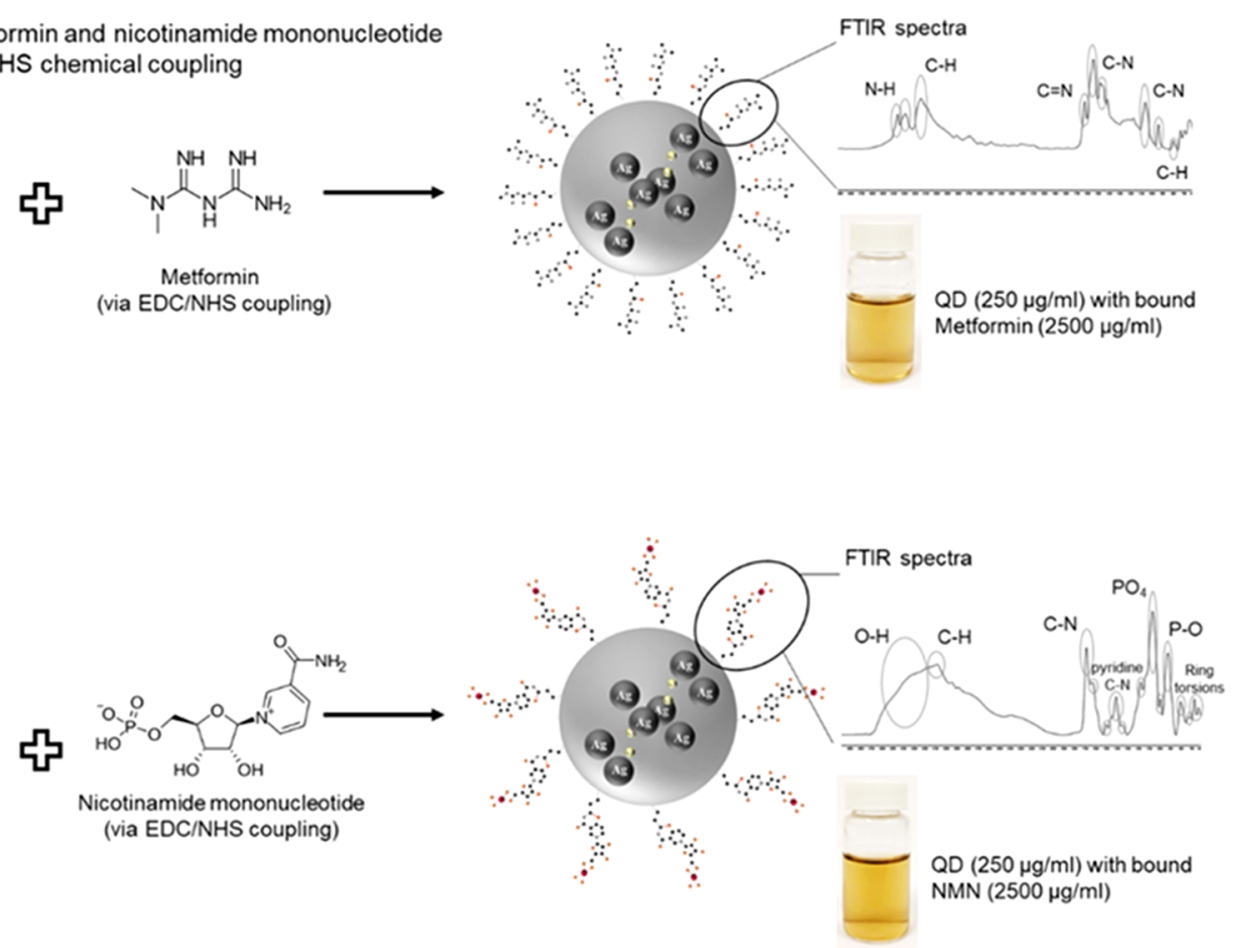

B. Quantum dot sizing

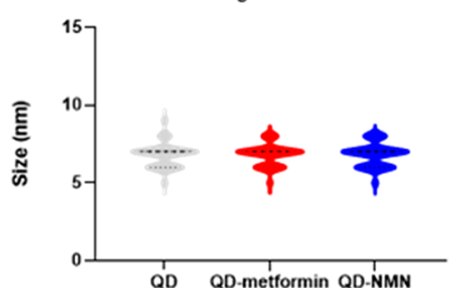

E. Loading efficiency low $(0.02 \mathrm{mg} / \mathrm{ml}) \mathrm{QD}$ concentration

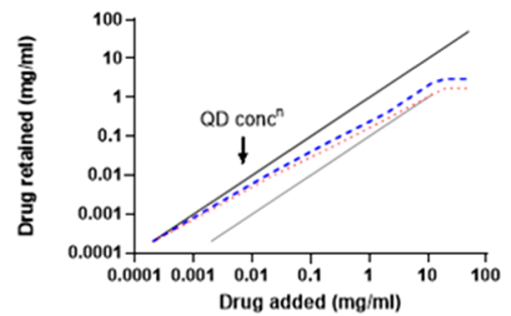

C. Hydrodynamic diameter

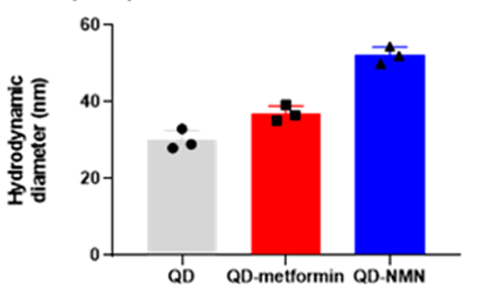

F. Loading efficiency high (2 mg/ml) QD concentration

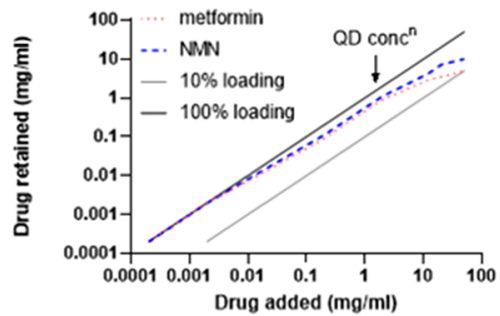

D. Zeta potential

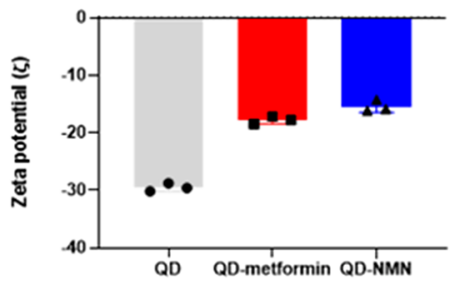

G. Maximal ligands per QD

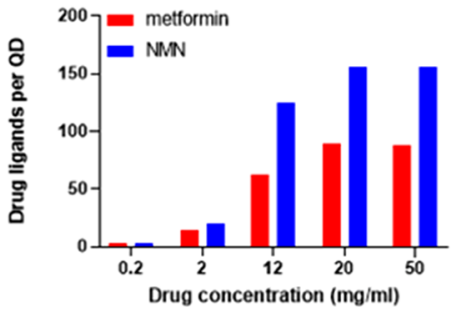

Figure 1. Conjugation and characterization of $\mathrm{Ag}_{2} \mathrm{~S}$ quantum dots (QDs) with metformin and nicotinamide mononucleotide (NMN). (A) Water-soluble QDs with a hydrophilic external layer of carboxylic acid molecules on their surface (as shown using Fourier transform infrared (FTIR) microscopy spectral analysis) are conjugated with metformin or NMN using EDC/NHS chemical coupling. Repeat FTIR spectra analysis demonstrates an external layer of drug conjugate on these QDs. (B) QDs (gray) with/without drug attachment (QD-metformin (red) and QD-NMN (blue)) demonstrated similar sizing when dried for visualization under transmission electron microscopy. Examination in solution showed drug attachment increases the hydrodynamic diameter $(C)$ and shifts zeta-potential toward 0 (D). The loading efficiency was measured using a low $(\mathrm{E})$ and high $(\mathrm{F})$ concentration $\left(\operatorname{conc}^{\mathrm{n}}\right)$ of QDs. The amount of drug retained following conjugation and $24 \mathrm{~h}$ at $\mathrm{pH} 7$ under dialysis was $100 \%$ when a greater ratio of QDs to drug was used. When greater concentration of drug compared to QDs was used, loading efficiency shifted toward $10 \%$. A maximal drug attachment ratio was observed for metformin $(90 \mathrm{mM} / 1 \mathrm{mM})$ and NMN $(150 \mathrm{mM} / 1 \mathrm{mM})(\mathrm{G})$.

and hepatoselectivity. These $7 \mathrm{~nm} \mathrm{Ag}_{2} \mathrm{~S}$ QDs rapidly accumulate in the liver within $0.5 \mathrm{~h}$ of oral administration and are cleared within $24-72 \mathrm{~h}$, with the window between open to therapeutic drug delivery to hepatocytes. ${ }^{10}$ We further demonstrated that the rapid absorption across the small intestine was via clathrinmediated endocytosis and micropinocytosis. ${ }^{10}$ This previous study showed that QD-mediated transport of metformin increased its bioavailability in the liver; we therefore sought to comprehensively examine the role of QDs as therapeutic drug carriers to the liver.

The liver plays a critical role in regulating the metabolic responses to nutrition. The canonical nutrient sensing pathways 

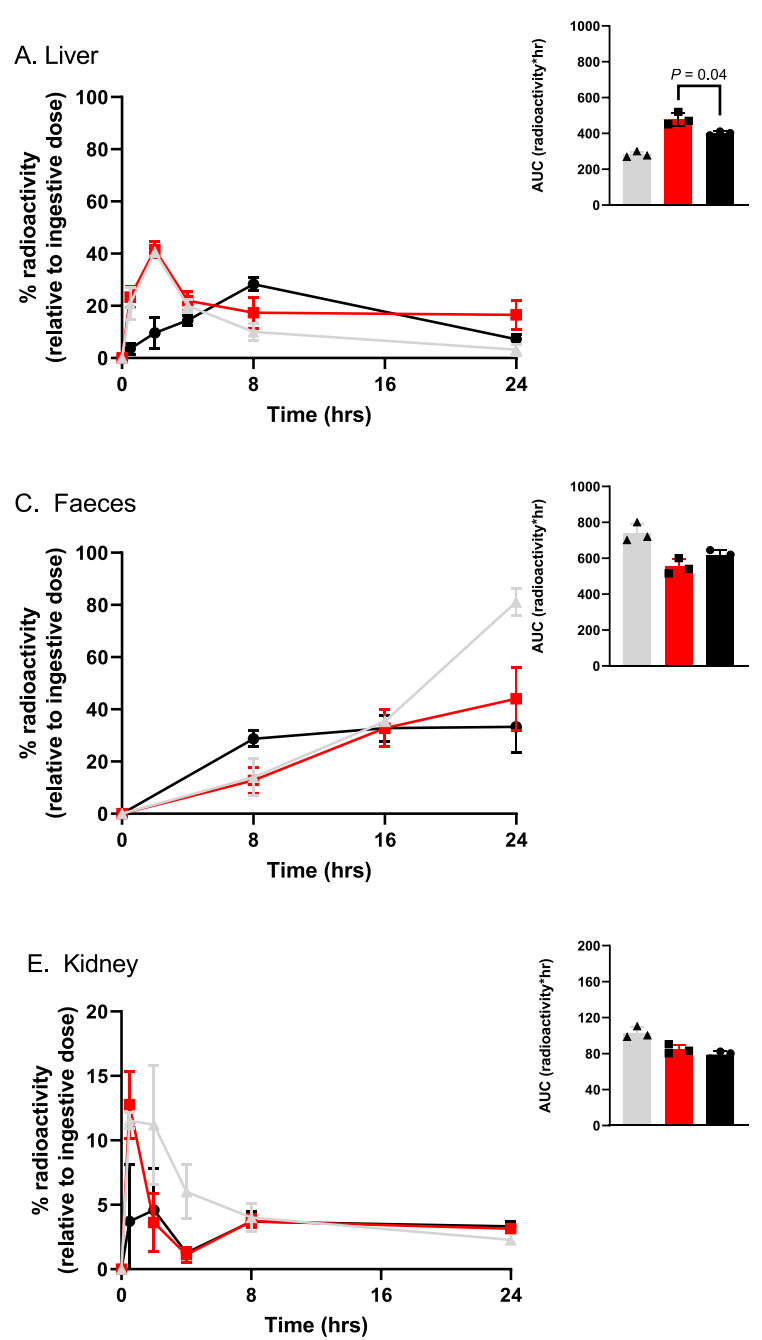
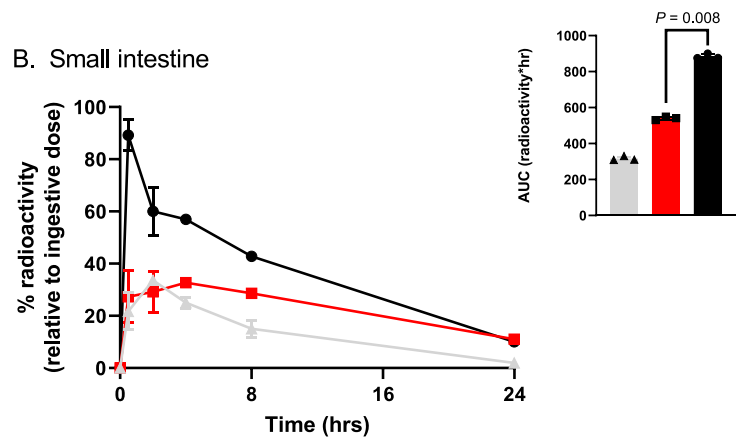

D. Blood
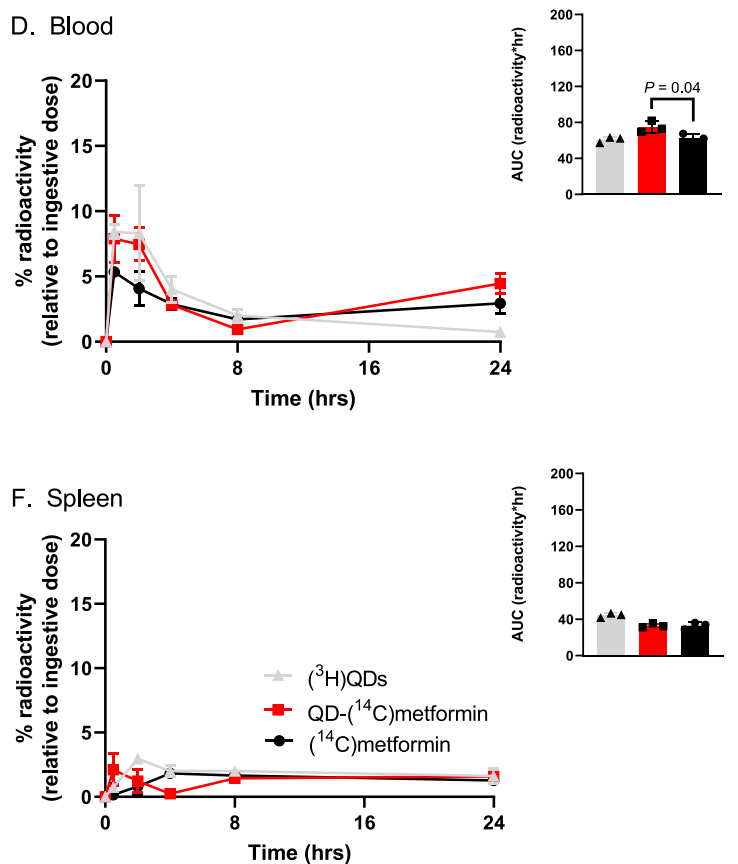

Figure 2. Pharmacokinetic and biodistribution data of $\left({ }^{3} \mathrm{H}\right)$ QDs (gray), $\left({ }^{14} \mathrm{C}\right)$ metformin (black), and QD- $\left({ }^{14} \mathrm{C}\right)$ metformin (red) following oral administration. Following ingestion, QDs, metformin, and QD-metformin accumulate in various organs. (A) Metformin uptake peaks in the liver $8 \mathrm{~h}$ after administration; attachment to QDs leads to an earlier peak at $2 \mathrm{~h}$. After $8 \mathrm{~h}$, QDs show faster liver clearance than the attached metformin, indicating detachment of drug from QDs. Over a $24 \mathrm{~h}$ period, a greater concentration of metformin is in the liver when it is conjugated to QDs, as shown by the greater area under the curve (AUC). (B) Persistence in the small intestinal lumen is reduced when metformin is attached to QDs; without attachment, $50 \%$ of metformin is localized to the intestine after $8 \mathrm{~h}$ compared to $25 \%$ of QD-metformin; this contributes to a greater AUC for metformin compared to that for QD-metformin. (C) Similar fecal clearance of metformin and QDmetformin was observed. (D) Blood concentration of metformin and QD-metformin demonstrated similar shifts; attachment to QDs allows for faster passage into blood; concentration is reduced by $8 \mathrm{~h}$ followed by re-entry into the blood. Comparison to QD clearance from blood suggests detachment of metformin from QDs similar to that observed in liver. (E) Kidney and (F) spleen demonstrate small accumulations of drug and QDs. Following $24 \mathrm{~h}$, less than 5\% of materials remain in these organs with no differences in AUC between QD or metformin alone. Data show mean \pm SD $(n=3$ per group, compared with Kruskal-Wallis test and post-hoc Dunn's method; $\alpha=0.05)$.

involved in these responses are $\mathrm{AMPK}$, sirtuin $/ \mathrm{NAD}^{+}, \mathrm{mTOR}$, and insulin signaling pathways. ${ }^{9}$ As well as being involved with metabolic responses such as insulin/glucose homeostasis, these nutrient sensing pathways are disrupted with aging, ${ }^{11}$ and medicines that target these pathways influence aging biology. ${ }^{9}$ For example, metformin, an extensively prescribed drug for type II diabetes mellitus, also increases lifespan in animal models via phosphorylation of AMPK. ${ }^{12} \mathrm{NAD}^{+}$is a cofactor for sirtuins and supplementation with a precursor of $\mathrm{NAD}^{+13}$ nicotinamide mononucleotide $(\mathrm{NMN})$, delays aging in mice ${ }^{14}$ and is also effective in the treatment of diet- and age-induced diabetes. ${ }^{15}$ We previously reported the effects of metformin and NMN on liver sinusoidal endothelial cells (LSECs) and the impact of aging on the responses. ${ }^{16,17}$ In vitro, QD-metformin was taken up by endocytosis rather than by its usual transporter, OCT1, and had greater impact on AMPK activation than metformin alone. $^{10}$

Here, we comprehensively evaluate and provide the framework for nanopharmaceutical evaluation. We examined hepatoselective, orally administered QD-metformin and QDNMN formulations to determine (i) their pharmacokinetic and pharmacodynamic properties, in particular, their effects on glucose/insulin metabolism in vitro and in vivo and the cellular pathways involved; (ii) the effects of old age on the physiological responses to these nanomedicines and drug agents alone; and (iii) the development of any toxicity following long-term administration of QDs. We show that QD-metformin and QDNMN have dramatically increased hepatic bioavailability and 100- to 1000-fold improvements in metabolic effects compared to drug alone. This potent effect is due to QD mediated 
improved pharmacodynamics, bypassing classical cellular uptake pathways and absorption. This is most evident in old mice that show improved insulin/glucose metabolism following 2 weeks of QD-NMN treatment but did not respond to NMN treatment alone. Finally, we observed no toxicity following 100 days of oral QD administration.

\section{RESULTS AND DISCUSSION}

Synthesis and Characterization of Drug Loading on $\mathbf{A g}_{2} \mathbf{S}$ QDs. The synthesis and phase transfer of these QDs was previously reported. ${ }^{10}$ The conjugation of metformin and NMN to the QDs was performed using a two-step chemical conjugation reaction. The first step involves EDC conjugation to carboxylic groups on the QDs. The second step uses an NHS catalyst for the formation of an amide bridge between these carboxylic acid groups and the primary amine group on metformin or NMN (Figure 1A).

Fourier transform infrared (FTIR) spectra demonstrated the change in surface topology from carboxylic groups to a chemical layer of metformin or NMN on the QDs (Figure 1A). The QDs retained their solubility index in water to an upper threshold of $500 \mu \mathrm{g} / \mathrm{mL}$; greater than this promoted aggregation. The polydispersity index (PDI) was $\mathrm{QD}=0.271 \pm 0.025$, QDmetformin $=0.236 \pm 0.038$, QD-NMN $=0.231 \pm 0.049$ (Supplementary Figure 1). The QD-drug complex maintained its $7 \mathrm{~nm}$ diameter (Figure 1B), with an increased hydrodynamic diameter and right shifted (toward 0 ) zeta-potential with drug attached (Figure 1C,D and Supplementary Figure 1). The increase in hydrodynamic diameter was relative to the size of the drug molecule attached: QD-metformin had a $25 \%$ increase, while QD-NMN had a 75\% increase in hydrodynamic diameter compared to that with QD alone. The increase in zeta-potential was related to the addition of positive charges from metformin and NMN.

The loading efficiency of the drugs was limited by the concentration of QDs which in turn limited the surface area for drug attachment. When the ratio of $\mathrm{QD} /$ drug was 100:1, the amount of drug retained on the surface of QDs after $24 \mathrm{~h}$ under dialysis approached $100 \%$. When the ratio was $1: 1,80 \%$ of the drug was retained. Finally, when the ratio was $1: 100$, only $10 \%$ of the drug retained on the surface of the QDs (Figure 1E,F). The upper limits for attachment of metformin and NMN to QDs were 90 and $150 \mathrm{mM}$, respectively, per $1 \mathrm{mM}$ QDs (Figure $1 \mathrm{G}$ ).

The drug loading efficiency of these $\mathrm{Ag}_{2} \mathrm{~S}$ QDs is high compared to that with other methods and QDs. Silica nanoparticles (NPs) were also observed to absorb metformin relative to the concentration of added material reaching a limit for entrapment of $21 \% \mathrm{v} / \mathrm{v}$ relative to the silica NPs. ${ }^{18}$ Entrapment methods are limited by the storage efficiency of internalized drug molecules. For example, Xu et al. ${ }^{19}$ used hollow zein NPs with an entrapment of $37 \%$ of metformin $\mathrm{v} / \mathrm{v}$ compared to the NPs. Comparatively, nanoparticles that have a surface coat of drug molecules retain more drug molecules. With regards to binding metformin, PLGA NPs retained 66$68 \% ;^{20,21}$ gold NPs retained $63 \% ;^{22}$ pectin NPs retained $68 \%{ }^{23}$ and BSA NPs retained $92 \%$. $^{24}$

Biodistribution and Pharmacokinetics of QD-Metformin. Nanomaterial drug transporters alter the biodistribution and pharmacokinetic properties of drugs. ${ }^{25}$ To investigate the effect of conjugation of metformin to QDs, radiolabeled $\left({ }^{14} \mathrm{C}\right)$ metformin was attached to tritium $\left({ }^{3} \mathrm{H}\right)$-labeled QDs. The results demonstrated that QDs substantially alter the distribution and pharmacokinetics of metformin. QD-metformin had
$25 \%$ increase in area under the curve (AUC) in the liver and blood and $60 \%$ lower AUC in the small intestine compared to that with metformin alone (Figure 2).

Unconjugated metformin took $8 \mathrm{~h}$ for half the dose to be absorbed from the small intestine, and at this time point, only $25 \%$ of the ingested dosage was distributed into the liver. This decreased to $5 \%$ at $24 \mathrm{~h}$ (Figure $2 \mathrm{~A}$ ). This indicates that only $25 \%$ of the dose of oral metformin is acting in the liver to promote hepatic glycemic regulation. Oral bioavailability is usually assessed from the concentration of a drug in the blood, and metformin has an oral bioavailability of $40-60 \%$ under fasting conditions; however, this is lower in the fed state. ${ }^{26,27}$ Data on the distribution into the target organ, in this case the liver, are critical because it directly influences pharmacological responses.

Comparatively, $\left({ }^{3} \mathrm{H}\right) \mathrm{QDs}$ and $\left({ }^{14} \mathrm{C}\right)$ metformin bound to QDs had a rapid clearance from the small intestine with only $25 \%$ of the ingested dosage remaining in the small intestine $30 \mathrm{~min}$ postadministration (Figure 2B). By the $2 \mathrm{~h}$ time point, $50 \%$ of the ingested dose was found in the liver and $10 \%$ in the blood and the kidneys. The blood concentration of QDs and metformin peaked at the $2 \mathrm{~h}$ time point, and the ${ }^{3} \mathrm{H}$ and ${ }^{14} \mathrm{C}$ radiolabels had similar distribution patterns until the $8 \mathrm{~h}$ time point (Figure 2). As no differences were observed between $\left({ }^{3} \mathrm{H}\right) \mathrm{QD}$ and $\mathrm{QD}$ $\left({ }^{14} \mathrm{C}\right)$ metformin, this suggests that the difference in their hydrodynamic diameter does not influence uptake from the small intestine and that the low $\mathrm{pH}$ environment of the stomach does not dissociate metformin from the QD prior to absorption into blood.

After $8 \mathrm{~h}$, the amount of drug and QDs in tissues and blood decreased, and this was associated with an increase in fecal elimination (Figure $2 \mathrm{C}) .\left({ }^{14} \mathrm{C}\right)$ metformin bound to QDs did not show the same increase in fecal elimination that was observed with QDs up to $24 \mathrm{~h}$ (Figure 2C); however, it did show an earlier peak in kidney tissue. These results suggest that the bond between metformin and QDs is cleaved in the liver, and the QDs are eliminated primarily via the bile and feces, while metformin is excreted via the urine. The bond between the QD and metformin is an amide bridge; therefore, it is likely that the cleavage of this bond is undertaken by hepatic cytochrome P450 enzymes. $^{28}$

Overall, the biodistribution data highlight that metformin transported to the liver by QDs enters the hepatocytes and persists for up to $24 \mathrm{~h}^{10}$ The liver has a wide range of effective processes to metabolize and eliminate xenobiotics including most drugs and nanomaterials. There are multiple potential barriers to prevent the uptake of nanomaterials including endocytosis and phagocytosis by Kupffer cells, LSECs, and infiltrating macrophages. Once taken up by hepatocytes, phase I and phase II metabolism combined with efficient biliary excretion ensure rapid metabolism and clearance of xenobiotics. Metformin is released from QDs into the hepatocytes during this process with QDs cleared into the bile for fecal elimination. It is of note that nanocrystallization of medicines are associated with similar improvements in biodistribution of medicines. ${ }^{25,29}$ It is generally considered that nanocrystal medicines have greater bioavailability due to improved solubility and not cellular targeting. ${ }^{29,30}$ Our results also raise the possibility that the improved bioavailability of nanocrystals may also be due to their size-dependent uptake in the small intestine and liver. ${ }^{31}$

Pharmacodynamic Properties of QD-Metformin and QD-NMN. To characterize the pharmacodynamic properties of QD-metformin and QD-NMN, we compared the in vivo dose- 
A. Metformin treatment on oGTT

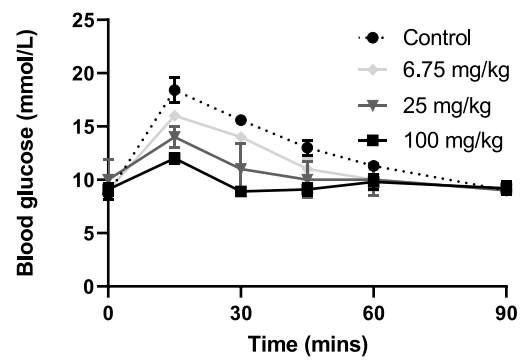

C. PD: metformin vs QD-metformin
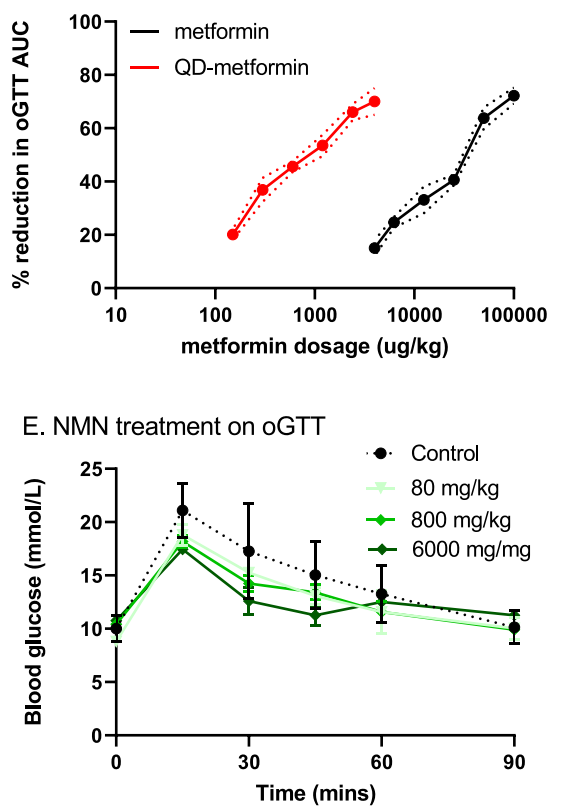

G. PD: NMN vs QD-NMN

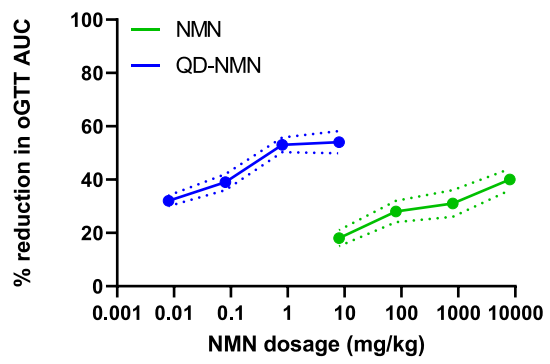

B. QD-metformin treatment on oGTT
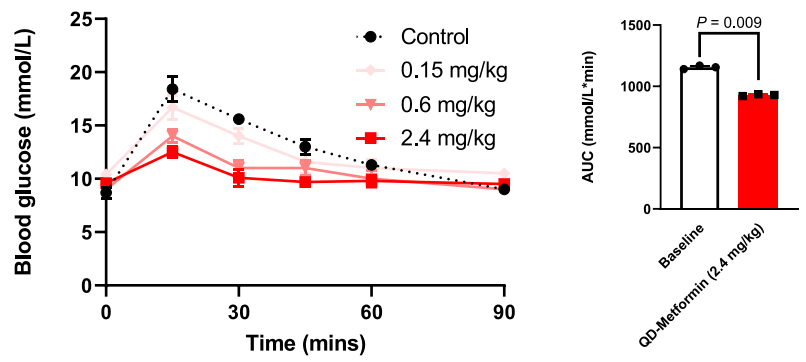

D. PK/PD: metformin vs QD-metformin
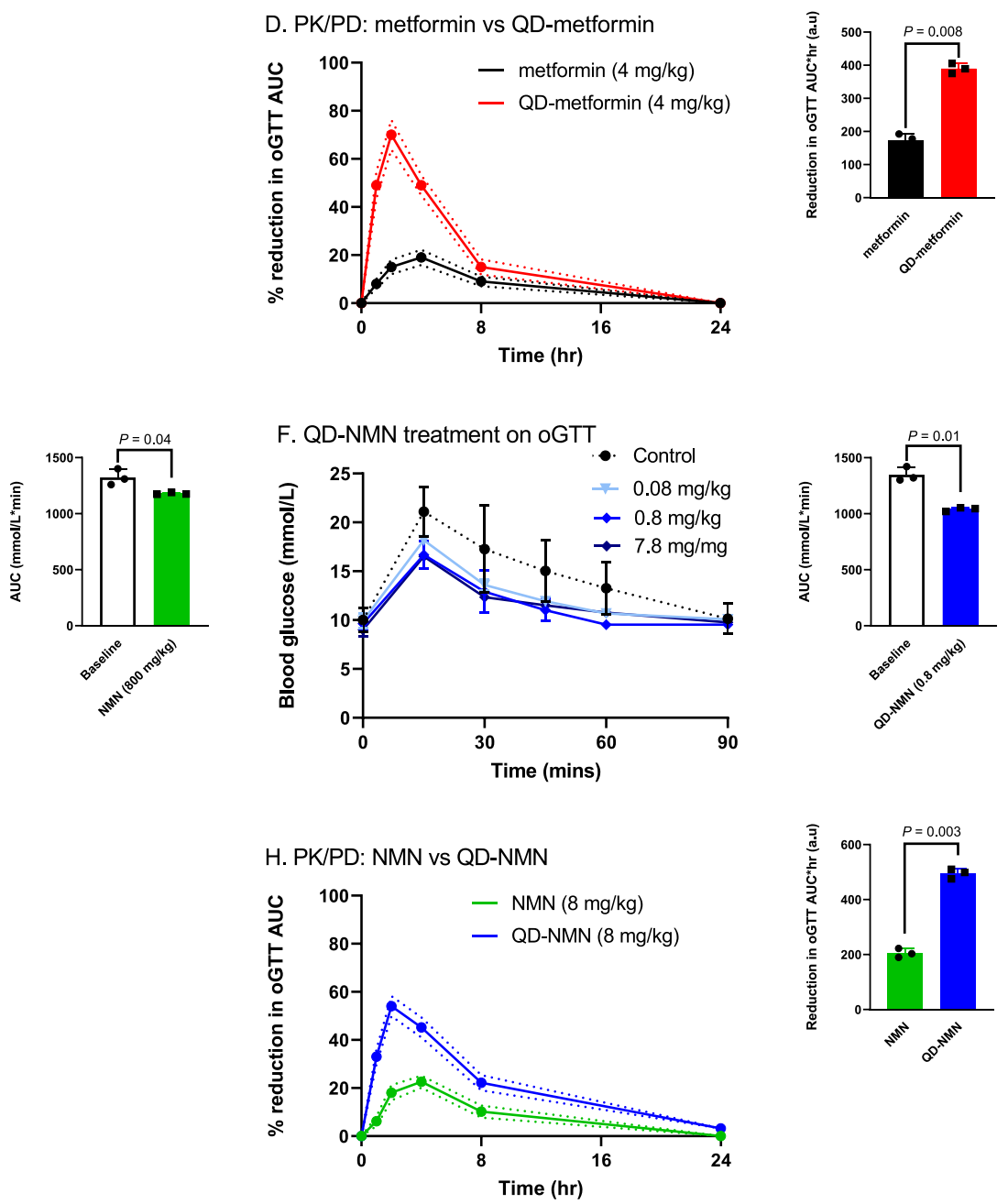

Figure 3. In vivo pharmacodynamics and PK/PD of metformin and NMN with and without attachment to QDs. (A) Metformin (black) and (B) QD-metformin (red) given by oral gavage $2 \mathrm{~h}$ prior to an oral glucose tolerance test (oGTT) demonstrated a dose-dependent reduction in the time taken to clear glucose from the blood and AUC. (C) Comparison between dosage of metformin alone and QD-metformin and the percentage of reduction in oGTT AUC demonstrates QD-metformin induces the same effect as drug alone at $1 \%$ of the dosage given. (D) Comparison of the effects of the same dosage of metformin with/without conjugation to QDs on the reduction in oGTT AUC. oGTTs were performed 0.5, 2, 4, 8, or $24 \mathrm{~h}$ following gavage. (E) NMN (greenh) and (F) QD-NMN (blue) given by oral gavage $2 \mathrm{~h}$ prior to an oGTT demonstrated a dose-dependent reduction in the time taken to clear glucose from the blood and AUC. (G) Comparison in the concentration of drug given between NMN alone and QD-NMN and the percentage of reduction in oGTT AUC demonstrates QD-NMN induces the same effect as drug alone at $0.1 \%$ of the dosage given. (D) Comparison of the effects of the same dosage of NMN with/without conjugation to QDs on the reduction in oGTT AUC. oGTTs were performed $0.5,2,4,8$, or $24 \mathrm{~h}$ following gavage. Data show mean \pm SD $(n=3$ per group). Statistical test: Kruskal-Wallis tests with a post-hoc Dunn's method; $\alpha=0.05$.

response effects with the nonconjugated medicines. A single oral dose of metformin or NMN with or without conjugation to QDs reduced blood glucose levels in oral glucose tolerance tests (oGTT) in 3 month old mice. Metformin when given alone $2 \mathrm{~h}$ prior to oGTT had a maximal effect of a $75 \%$ reduction in the
AUC at a dose of $100 \mathrm{mg} / \mathrm{kg}$ (Figure 3A). Comparatively, a dose of only $2.4 \mathrm{mg} / \mathrm{kg}$ of $\mathrm{QD}$-metformin was required to promote the same reduction in AUC (Figure 3B). There were no differences in the shape of the oGTT curves and metformin and QD-metformin had similar $T_{\max }$. Overall, a 100-fold lower dose 
A. In vivo treatment effects on PAMPK/AMPK

B. In vivo treatment effects on SIRT1
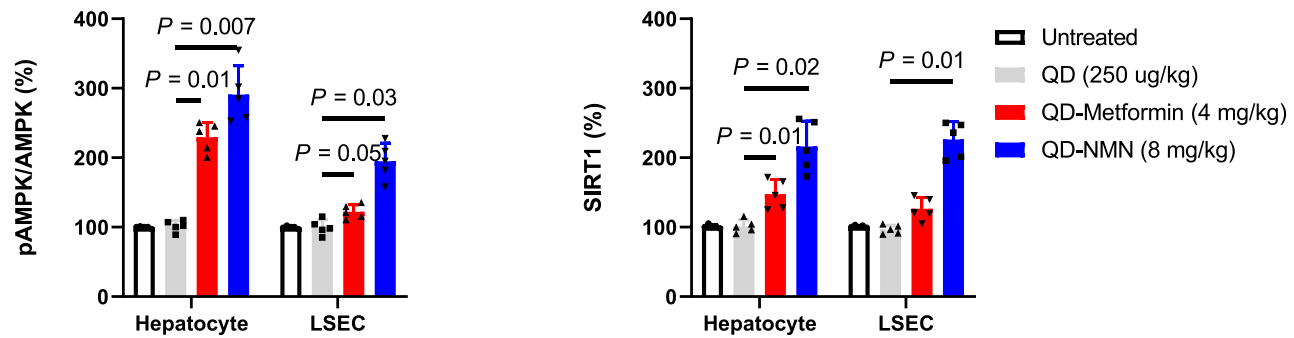

C. In vivo treatment effects on cGMP
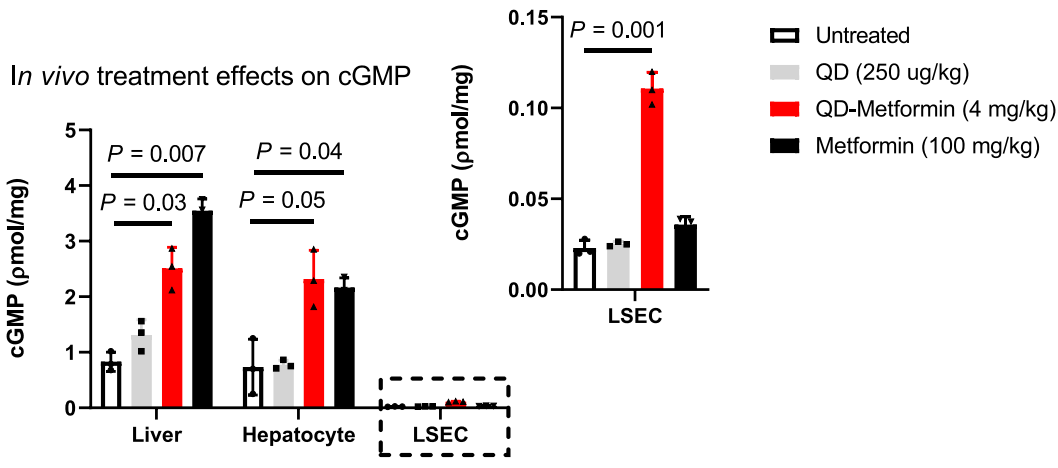

D. In vivo treatment effects on NAD (total) $\mathrm{NAD}^{+}$\& NADH
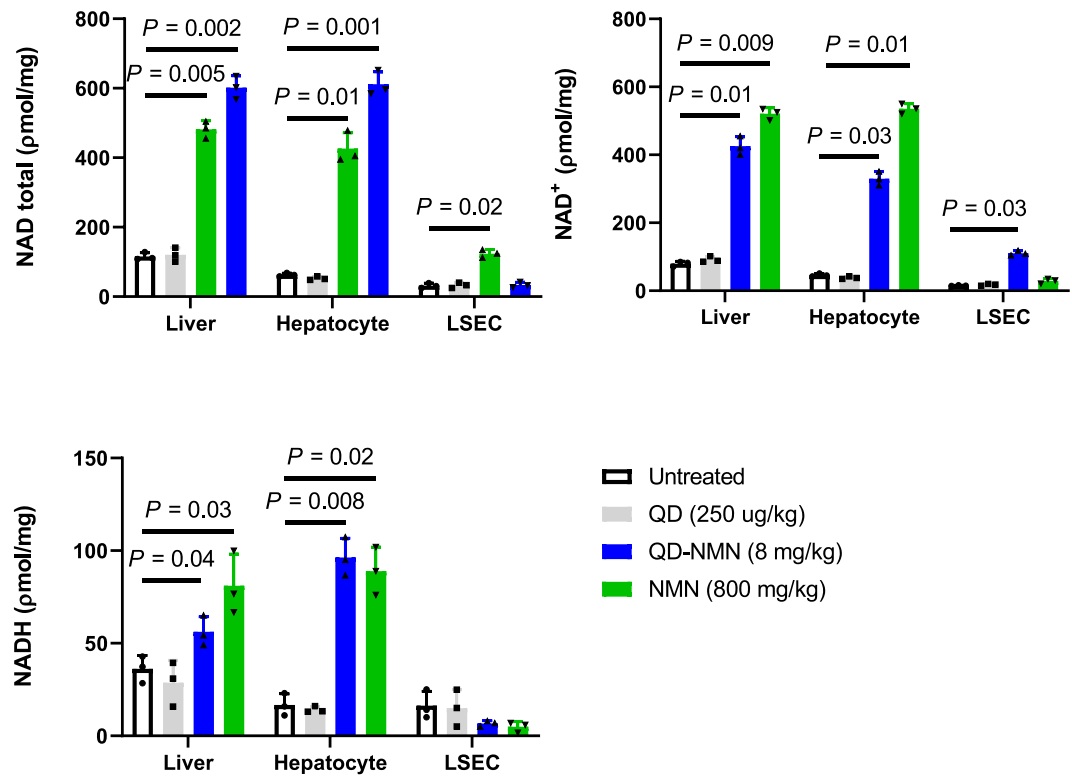

Figure 4. In vivo molecular pathways promoted by QD-drug treatment compared to drug alone. Mice received an oral gavage of water (white), QDs (gray), QD-metformin (red), metformin (black), QD-NMN (blue) or NMN (green) (dosages are given per figure) $2 \mathrm{~h}$ prior to liver tissue collection and hepatocyte and liver endothelial cell isolations. (A) p-AMPK/AMPK and (B) SIRT1 were analyzed by Western blots and normalized to $\beta$-tubulin expression, percentage changes relative to untreated controls are compared between groups. (C) cGMP by a commercial ELISA, and (D) NAD total, $\mathrm{NAD}^{+}$and $\mathrm{NADH}$ by a commercial NAD/NADH assay. Westernblot images are provided in Supplementary Figure 2. ELISA and assay protein measurements are relative to $\mathrm{mg}$ of liver tissue or protein from isolated cells. Data show mean \pm SD (A,B: $n=5, \mathrm{C}-\mathrm{D}: n=3$ per group). Statistical test: (A,B) one-way-ANOVA with post-hoc Bonferroni test; (C,D) Kruskal-Wallis tests with a post-hoc Dunn's method; $\alpha=0.05$.

of QD-metformin promoted comparable effects to metformin alone (i.e., $2 \log _{10}$ left shift in $\mathrm{AUC}_{50}$ ) (Figure 3C). The optimal time for administering metformin was $4 \mathrm{~h}$ prior to oGTT, while for QD-metformin, it was only $2 \mathrm{~h}$, consistent with its more rapid absorption and uptake by the liver. This shift in optimal timing of the dose correlates with the peak concentration of $\left({ }^{14} \mathrm{C}\right)$ metformin within the liver (Figure $\left.2 \mathrm{~A}\right)$. When the same doses of metformin with and without $Q D$ conjugation were administered between 0.5 to $24 \mathrm{~h}$ prior to oGTT, it was found that QD-metformin had a greater effect in reducing the oGTT response at all time points (Figure 3D) up until $24 \mathrm{~h}$ when no effect was seen with either treatment.

There have been a few other studies evaluating the effects of nanocarriers on the pharmacodynamic effects of metformin in 
A. In vitro endocytosis in hepatocytes from $3 \mathrm{mth}$ old mice

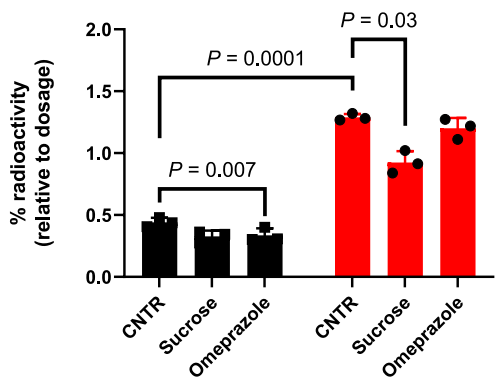

C. In vitro treatment in isolated hepatocytes from $3 \mathrm{mth}$ old mice

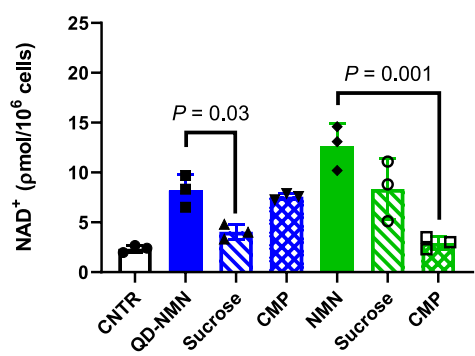

B. In vitro endocytosis in hepatocytes from $18 \mathrm{mth}$ old mice

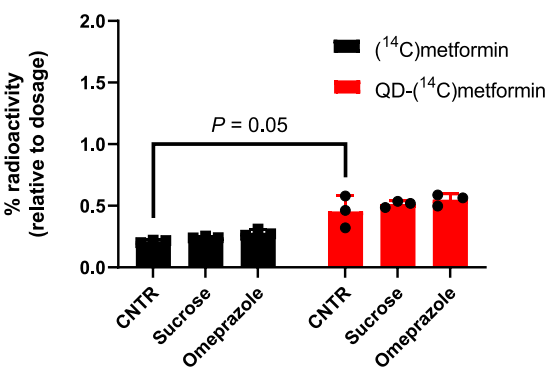

D. In vitro treatment in isolated hepatocytes from $24 \mathrm{mth}$ old mice

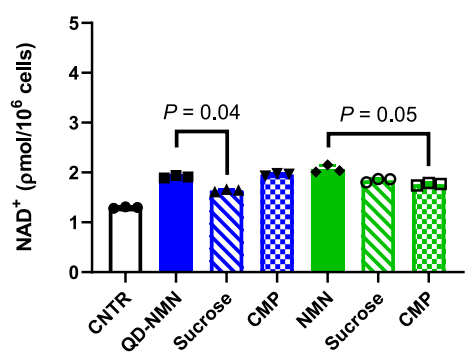

E. In vitro cell viability in hepatocytes from $3 \mathrm{mth}$ old mice

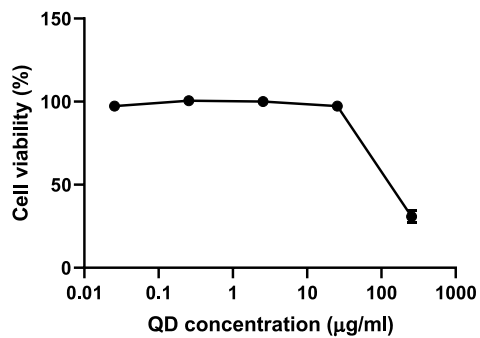

Figure 5. In vitro drug/QD-drug treatment on isolated hepatocyte endocytosis/activation and LSEC fenestrations. Hepatocytes were isolated from young 3 months old mice (A) and old 18 months old mice (B). Hepatocytes were nonpretreated control (CNTR) or pretreated for 0.5 h with sucrose $(0.5 \mathrm{M})$ to block clathrin-mediated endocytosis and micropinocytosis or omeprazole (10 $\mu \mathrm{M})$ to block endocytosis via protein pumps. Cells were then treated for $2 \mathrm{~h}$ with radiolabeled $\left({ }^{14} \mathrm{C}\right)$ metformin (black) or QD $\left({ }^{14} \mathrm{C}\right) \mathrm{metformin}(\mathrm{red})$. (C) Young and (D) old hepatocytes were isolated and either nonpretreated or pretreated with sucrose (stripes) or cytidine 5-monophosphate (CMP) (spots) an inhibitor of dephosphorylation of NMN. Cells were then treated with QD-NMN (blue) or NMN (green) for 2 h. Cells were then lysed and NAD ${ }^{+}$ measured by NAD/NADH assay. (E) Young hepatocytes were isolated and incubated for $2 \mathrm{~h}$ with increasing concentration of QDs ( $1 \mathrm{nM}$ to 10 $\mathbf{m M}$ ). Cell viability was measured with an MTT assay. Data show mean \pm SD ( $n=3$ per group, compared with Kruskal-Wallis tests and posthoc Dunn's method; $\alpha=0.05$ ).

vivo. ${ }^{32}$ PLGA nanoparticles loaded with metformin $(10 \mathrm{mg} / \mathrm{kg})$ reduced the AUC of oGTTs streptozotocin-treated diabetic rats by $60 \%$ when given by injection $30 \mathrm{~min}$ prior to the glucose dose. ${ }^{20}$ In a similar study, oral alginate nanocapsules loaded with metformin $(46.7 \mathrm{mg} / \mathrm{kg}$ ) reduced the AUC of oGTT by $20 \%$ compared with metformin alone administered by injection (150 $\mathrm{mg} / \mathrm{kg}){ }^{22}$ The QD-metformin used in our study has considerably greater potency than the metformin nanomedicines reported in these studies. Moreover, our QDmetformin was administered orally compared to these previous studies where the metformin nanomedicines were administered by injection.

NMN was not as potent as metformin in terms of reducing the AUC of the oGTT. NMN given alone promoted a maximal 50\% reduction in the AUC at a dose of $8000 \mathrm{mg} / \mathrm{kg}$ (Figure 3E), while QD-NMN led to a similar reduction in the oGTT at a dose of only $0.8 \mathrm{mg} / \mathrm{kg}$ (Figure 3F). Overall, QD-NMN achieved the same effect on oGTT with $1 / 1000$ of the dose NMN alone
(Figure 3G). Examining a range of time points from 0.5 to $24 \mathrm{~h}$, it was found that QD-NMN had its optimal effect when given $2 \mathrm{~h}$ prior to oGTT, while NMN alone was optimal when given $4 \mathrm{~h}$ prior to oGTT. At all dosing time points, QD-NMN had a greater effect on oGTT than equidoses of NMN alone (Figure $3 \mathrm{H})$. As far as we are aware, other nanocarrier methods for the drug delivery of $\mathrm{NMN}$ (or related compounds, $\mathrm{NAD}^{+}$or nicotinamide riboside) have not been reported. Our studies indicate that $\mathrm{Ag}_{2} \mathrm{~S}$ QDs are very effective carriers for the hepatic uptake of NMN.

Mechanisms for the Uptake and Activity of QDMetformin and QD-NMN. The majority of nanomaterials are taken up by cells via endocytosis. ${ }^{33}$ Endocytosis is undertaken by clathrin- and caveolin-mediated pathways and micropinocytosis and is geared toward subsequent degradation of materials within lysosomes, ${ }^{33,34}$ which of course limits the effect of nanomedicines. Therefore, we investigated the mechanisms for the cellular uptake of QD-metformin and 
A. Schematic of in vivo QD and NMN treatments on metabolic parameters and toxicity in aging mice

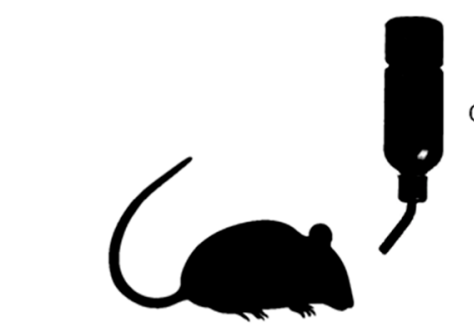

\section{$\underline{\text { Treatments }}$}

Untreated

or QD-NMN $(\underline{8 \mathrm{mg} / \mathrm{kg} / \text { day })}$

NMN $(800 \stackrel{\text { or }}{\mathrm{mg} / \mathrm{kg} / \text { day })}$

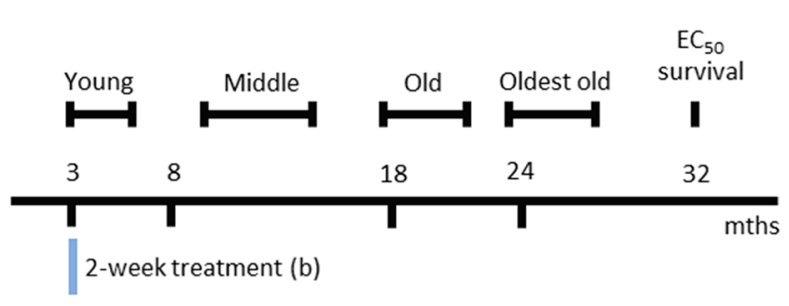

2-week treatment (c)

2-week treatment (d)

100-day QD toxicity study (320 $\mu \mathrm{g} / \mathrm{kg} /$ day) (Fig 8)
B. 2-week treatment in $3 \mathrm{mth}$ old mice on metabolic parameters
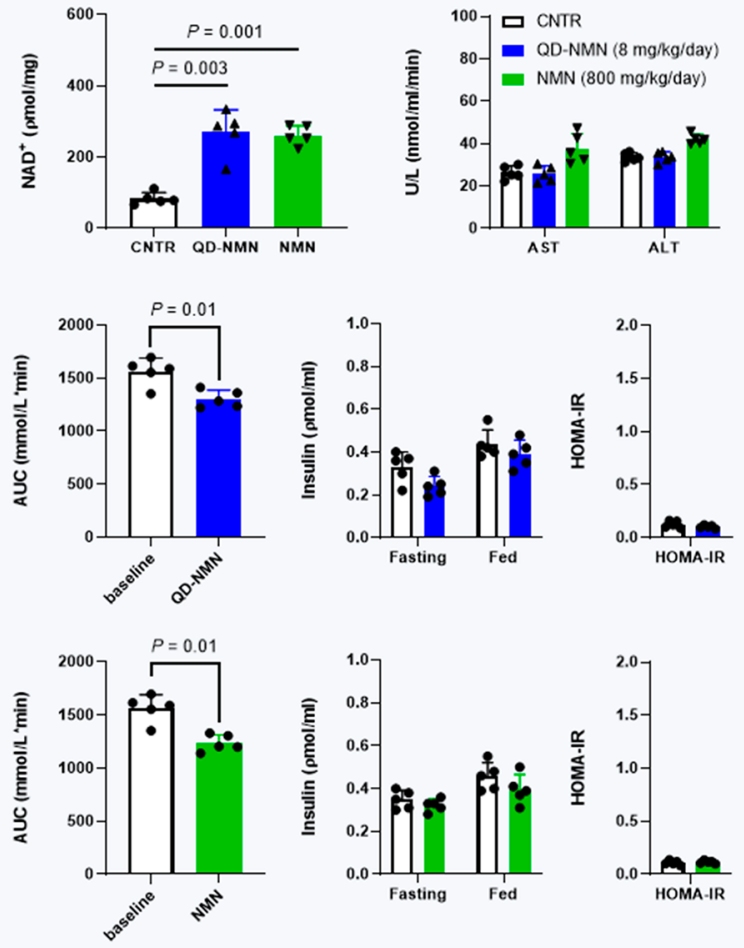

C. 2-week treatment in $18 \mathrm{mth}$ old mice on metabolic parameters

D. 2-week treatment in $24 \mathrm{mth}$ old mice on metabolic parameters
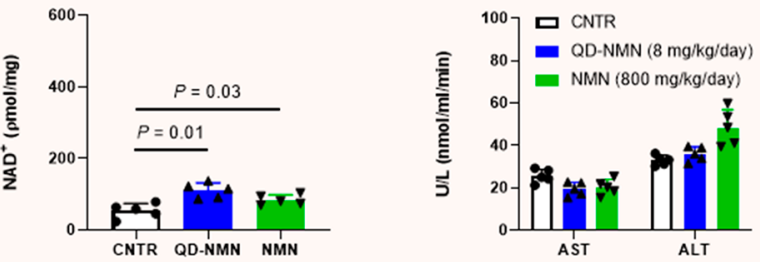
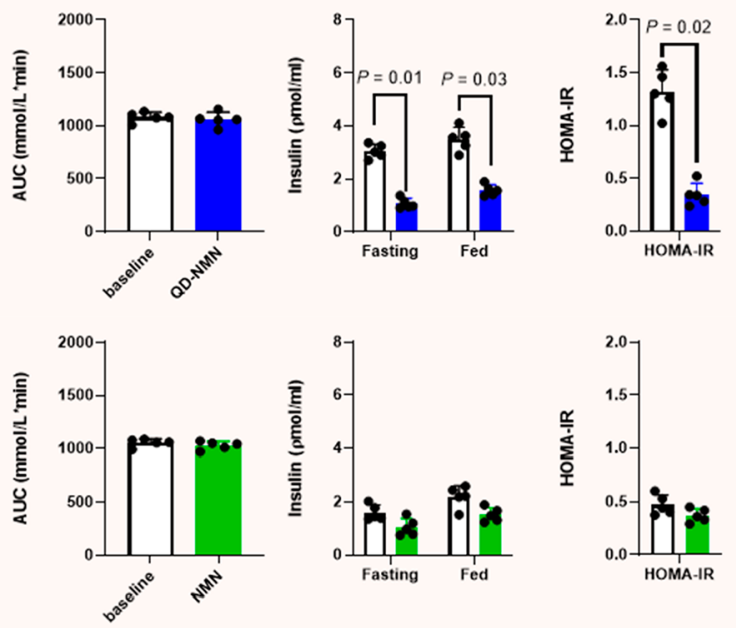
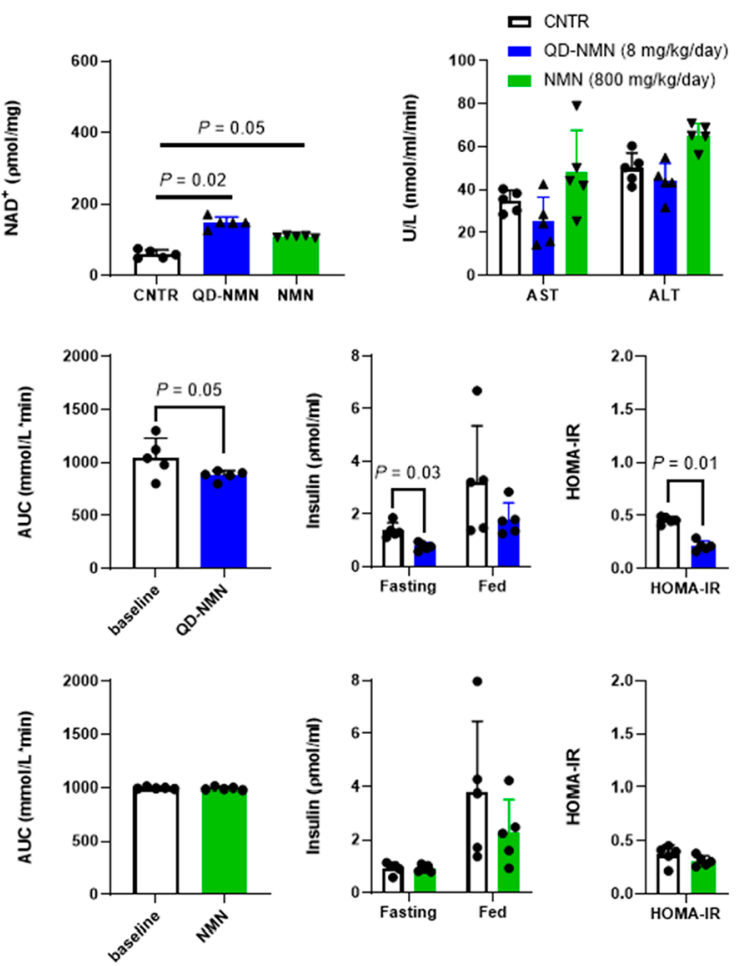

Figure 6. Overview of 2-week in vivo treatment with QD-NMN (blue) and NMN (green) in 3, 18, and 24 month old mice on metabolic parameters and toxicity. (A) schematic of experimental treatments and ages of intervention. (B-D) Effects of treatment in 3 month (B), 18 month (C), and 24 month (D) old mice. Data show liver NAD ${ }^{+}$, blood AST, and ALT; before and after treatment: oral glucose tolerance test area under the curve (AUC), fasting and fed insulin and HOMA-IR. Comprehensive data shown in Supplementary Figures 3-6. Data show mean \pm SD ( $n=5$ per group). Statistical test: one-way-ANOVA with post-hoc Bonferroni test; $\alpha=0.05$.

QD-NMN and compared the effects of these drugs, with and without conjugation to QDs, on their intracellular targets.
Metformin acts via phosphorylation of AMPK and activates cGMP downstream of this, as we have reported in hepatocytes 
and LSECs. ${ }^{9,16}$ Mice treated with either metformin or QDmetformin demonstrated upregulation of $\mathrm{pAMPK} / \mathrm{AMPK}$ and cGMP in hepatocytes following doses of $100 \mathrm{mg} / \mathrm{kg}$ metformin and $4 \mathrm{mg} / \mathrm{kg}$ QD-metformin (Figure $4 \mathrm{~A}$ and Supplementary Figure 2). QD-metformin, but not metformin alone, promoted activation of AMPK in LSECs (Figure 4A and Supplementary Figure 2). This is consistent with our previous study showing uptake of $\mathrm{Ag}_{2} \mathrm{~S}$ QDs by LSECs. ${ }^{10}$ Treatment of the immortal LSEC cell line, SK-Hep1, with metformin demonstrates upregulation of $\mathrm{pAMPK}$ and production of endothelial nitric oxide synthase (eNOS) (Supplementary Figure 3). Previously, we showed a 12 month $0.1 \%$ metformin $\operatorname{diet}(75 \mathrm{mg} / \mathrm{kg} /$ day $)$ from 3 to 15 months in mice induces liver endothelium fenestration changes, suggesting AMPK activation in these cells; however, this required prolonged treatment. ${ }^{16}$

Mice treated with either NMN or QD-NMN demonstrated similar effects on SIRT1 activity, total $\mathrm{NAD}$ and $\mathrm{NAD}^{+}$in liver, hepatocytes, and LSECs (Figure 4 and Supplementary Figure 2). Similar increases in total $\mathrm{NAD}$ and $\mathrm{NAD}^{+}$were observed for $800 \mathrm{mg} / \mathrm{kg} \mathrm{NMN}$ and $8 \mathrm{mg} / \mathrm{kg}$ QD-NMN treatments. QDNMN, but not NMN alone, increased these concentrations in LSECs (Figure 4D). Within the SK-Hep1 cell line, QD-NMN promotes upregulation of SIRT1, pAMPK, eNOS, and peroxisome proliferator-activated receptor $\gamma$ coactivator $1 \alpha$ (PCG-1 $\alpha$ ) (Supplementary Figure 3). Together these data indicate that the treatment effects of both metformin and NMN on their intracellular targets in hepatocytes are not influenced by conjugation with QDs and that conjugation enables considerably less dosage to be administered to achieve the same treatment effect. However, conjugation with QDs leads to additional effects on LSECs because these cells avidly take up QDs.

Comparisons of the effectiveness of QD-metformin to QD$\mathrm{NMN}$ indicate that QD-NMN allows for a greater reduction in dosage (compared to NMN) than with QD-metformin (compared to metformin alone). Mice treated with QD-NMN $(8 \mathrm{mg} / \mathrm{kg})$ had a greater increase in $\mathrm{pAMPK} / \mathrm{AMPK}$ and SIRT 1 than mice treated with QD-metformin $(4 \mathrm{mg} / \mathrm{kg})$ in the isolated hepatocytes and LSECs (Figure 4A-C). This effect may be due to the improved transport of QD-NMN across the small intestine and prevention of the utilization by gut microbiota (NMN is readily used by, and facilitates growth of E. coli),${ }^{35}$ a wider therapeutic effect window $(0.01-10 \mathrm{mg} / \mathrm{kg}$ QD-NMN vs $0.2-5 \mathrm{mg} / \mathrm{kg}$ QD-metformin (Figure 3C,G), and greater cellular activation of AMPK and SIRT1 with QD-NMN compared to QD-metformin (Figure 4A,C).

The cellular uptake of metformin is usually mediated by the transporter OCT1, which is inhibited by omeprazole. ${ }^{36}$ Consistent with this, we found that omeprazole inhibited the uptake of $\left({ }^{14} \mathrm{C}\right)$ metformin by isolated hepatocytes from young mice (Figure 5A). However, the uptake of $\left({ }^{14} \mathrm{C}\right)$ metformin conjugated with QDs was not inhibited by omeprazole. Instead, the uptake of $\left({ }^{14} \mathrm{C}\right)$ metformin conjugated with QDs was inhibited by sucrose, which is an inhibitor of clathrin-mediated endocytosis and micropinocytosis (Figure 5A). This result indicates that conjugation of metformin with QDs changes its cellular uptake from transport by OCT 1 to clathrin-mediated endocytosis in hepatocytes isolated from young mice.

A key finding from this work and our previous study ${ }^{10}$ is that QDs and QDs coated with metformin are absorbed from the small intestine and taken up by hepatocytes via clathrinmediated endocytosis. This is supported by our QD-NMN experiments that also show clathrin-mediated endocytosis
(Figure 5C); furthermore, previous studies have shown clathrin-mediated endocytosis of QDs in vitro and nanocrystals in vivo. ${ }^{37,38}$ Overall this suggests that size, shape, and charge are what facilitates this mechanism and that drug surface molecules do not direct cellular absorption or uptake. An interesting concept emerges from this; nanoreformulations of oral drug molecules have greater bioavailability and improved pharmacodynamics than the drug molecule alone, ${ }^{25}$ and these nanocrystal structures may also be taken up by clathrin-mediated endocytosis. Nanoreformulation of drug molecules has a high cost for research and development and toxicity and safety testing, ${ }^{39}$ and it may be possible that using a core nanocrystal and attachment of the drug to the surface may perform the same function as these reformulations without costly development and testing.

Hepatocytes isolated from old mice exhibited overall reduced endocytosis compared to young mice (Figure 5B), but the effects of omeprazole and sucrose on metformin uptake were similar to those seen in young mice. However, in hepatocytes isolated from old mice, uptake of metformin was greater when it was bound to QDs compared to metformin alone (Figure 5B).

The cellular uptake of NMN requires dephosphorylation to nicotinamide riboside for transport into hepatocytes, then rephosphorylation before being used to replenish $\mathrm{NAD}^{+}$ levels. ${ }^{40}$ Treatment of hepatocytes isolated from both young and old mice with NMN or QD-NMN led to increased NAD and $\mathrm{NAD}^{+}$levels. Pretreatment with cytidine 5 -monophosphate, an inhibitor of NMN dephosphorylation, ${ }^{40}$ inhibited the uptake of NMN by hepatocytes (Figure 5C,D); however, QDNMN was unaffected by cytidine $5^{\prime}$-monophosphate pretreatment, highlighting again a change in cellular uptake pathway (Figure 5C,D). Overall, treatment response was substantially lower in hepatocytes from old mice. The in vitro effect of QDs on cell viability in isolated hepatocytes from young mice was also examined in these experiments. Cell viability was influenced only when QD concentration exceeded $256 \mu \mathrm{g} / \mathrm{mL}$ (Figure $5 \mathrm{E}$ ).

Effects of 2 Weeks of Treatment with QD-NMN versus NMN in Young and Old Mice. NMN improves metabolic outcomes and influences the aging process. Old age influences metabolic outcomes, with an increase in insulin resistance and prevalence of diabetes mellitus. A previous study has shown that NMN improved oGTT in old diabetic animals, ${ }^{15}$ and NAD levels decline with increasing age. ${ }^{41}$ Here, we carried out in vivo experiments to determine whether QD-NMN, which only targets the liver, has metabolic outcomes similar to that with NMN alone, which is systemically bioavailable. We also wanted to determine whether the substantial increase in the potency of QD-NMN that we demonstrated in acute in vitro experiments was retained in longer term studies under in vivo conditions. To determine the effects of old age on these outcomes, three age groups were studied: 3,18 , and 24 months of age. In these studies, mice were treated for 2 weeks with QD-NMN ( $8 \mathrm{mg} /$ $\mathrm{kg} /$ day) or NMN ( $800 \mathrm{mg} / \mathrm{kg} /$ day) administered in drinking water (Figure 6A and Supplementary Figures 4-7).

In 3 month old mice, QD-NMN and NMN both improved the oGTT and increased liver total NAD and NAD ${ }^{+}$levels by $3-$ fold but had no effects on body weight, insulin, or HOMA-IR (Figure 6B and Supplementary Figures 4 and 7). There were no differences in these responses between QD-NMN and NMN despite the 100-fold difference in dose.

Eighteen month old mice showed higher insulin levels, higher HOMA-IR, and lower total $\mathrm{NAD}$ and $\mathrm{NAD}^{+}$levels in the liver compared to those in young mice. In mice aged 18 months, QD- 


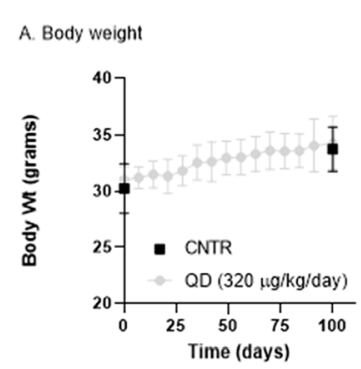

C. Plasma IL-6, MIP-2 (IL-8) \& IFN-*

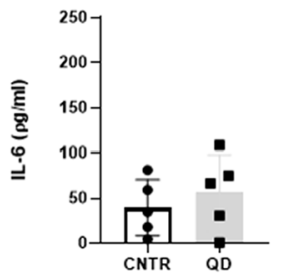

B. Liver function tests
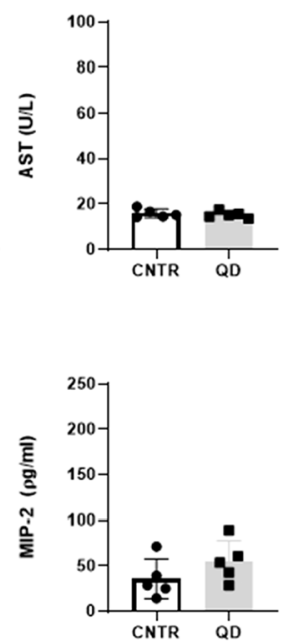

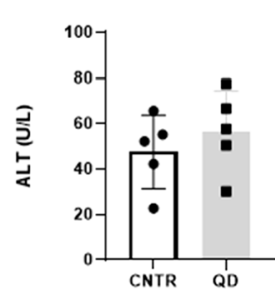

C. H\&E liver staining
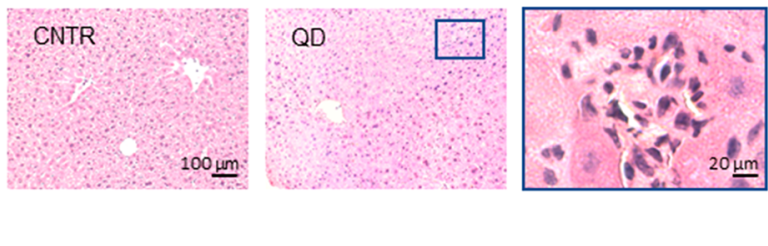

E. TNF $\alpha$ liver staining

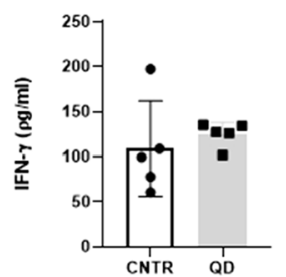

QD

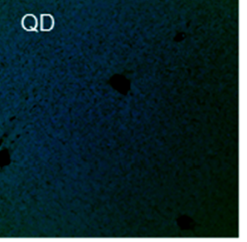

Negative CNTR
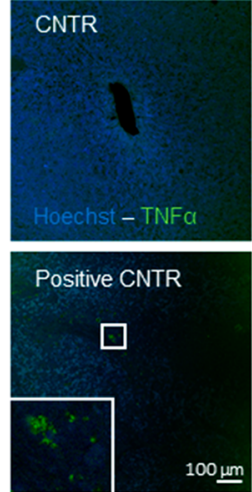

F. Sirius Red liver staining and METAR scoring
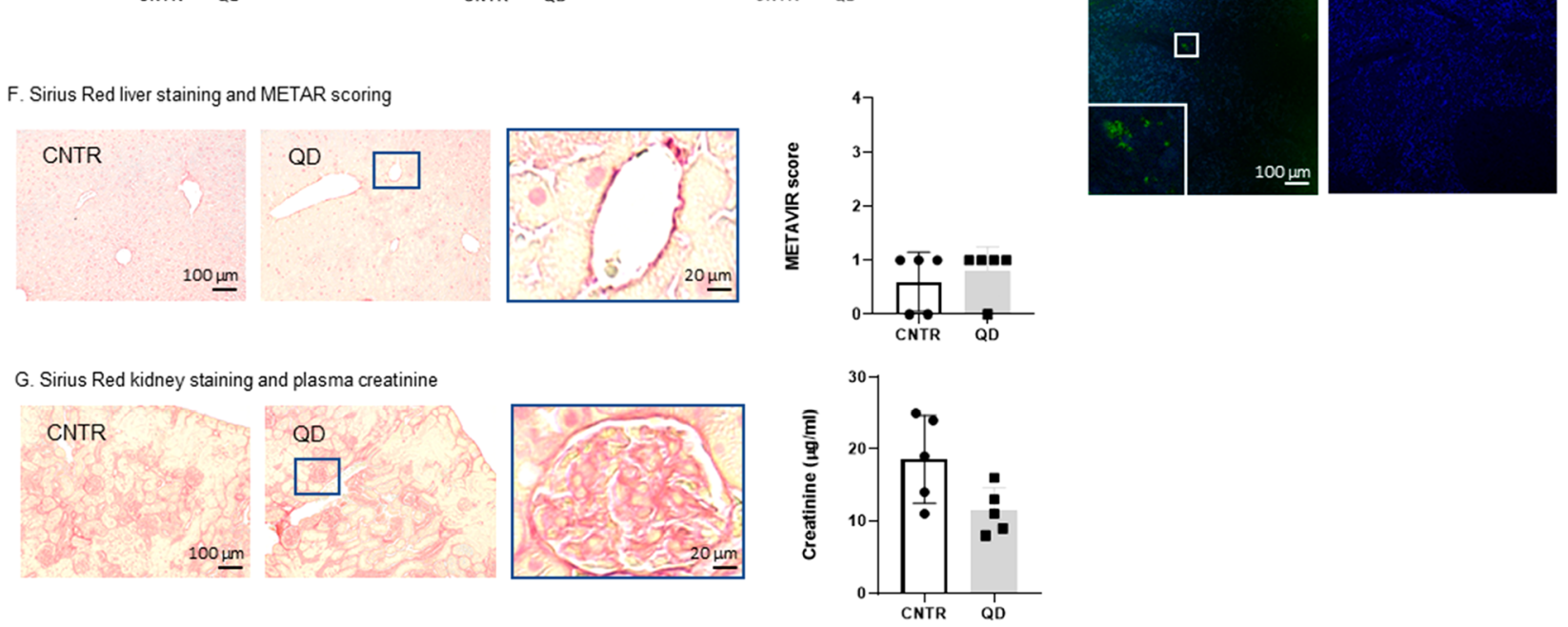

Figure 7. Effects of 100 day in vivo treatment with QDs $(320 \mu \mathrm{g} / \mathrm{kg} /$ day $)$. (A) Body weight of mice was collected every 7 days with control (CNTR) collected at day 0 and 100. (B) AST and ALT were not significantly influenced by treatment. (C) No changes in plasma IL-6, MIP-2 (mouse homologue of IL-8), or IFN- $\gamma$ were observed. (D) H\&E staining of the liver demonstrated sparse immune cell infiltration in QD-treated mice with no other pathohistological features. (E) TNF $\alpha$ staining did not show differences between CNTR and QD-treated mice, positive and negative control section from the spleen of control tissue. (F) Sirius Red staining of the liver and kidney (G) did not show differences between groups with low minimal fibrosis of the portal vein nor were differences observed in the METAVIR fibrosis score. In the kidney, no enlargement of the Bowman's capsules in the kidney was observed, and no change in plasma creatinine was shown. Data show mean \pm SD $(n=5$ per group compared with one-way-ANOVA and post-hoc Bonferroni test); $\alpha=0.05$.

NMN, but not NMN alone, was associated with lower fed and fasted insulin levels and lower HOMA-IR (Figure 6C and Supplementary Figures 5 and 7). In mice aged 24 months, QDNMN, but not NMN alone, was associated with improved oGTT and lower fasting insulin and lower HOMA-IR (Figure $6 \mathrm{D}$ and Supplementary Figures 6 and 7).

Insulin and glucose metabolism in the liver are influenced by NAD levels, ${ }^{9,42}$ which decrease with old age. ${ }^{41}$ In our study, the oldest mice (24 months) displayed lower levels of $\mathrm{NAD}^{+}$and higher levels of insulin and HOMA-IR compared to the youngest mice (3 months), consistent with other reports. ${ }^{15}$ Over 2 weeks, a low dose of orally administered QD-NMN led to increased liver $\mathrm{NAD}^{+}$levels and decreased insulin and HOMA-IR values in old mice. The dose of QD-NMN ( $8 \mathrm{mg} /$ $\mathrm{kg} /$ day) is substantially less than the dose of NMN alone $(800$ $\mathrm{mg} / \mathrm{kg} /$ day) or the dose reported by Yoshino et al. ${ }^{15}$ (500 mg/ $\mathrm{kg} /$ day by intraperitoneal injection) in their study of NMN supplementation in old diabetic mice. These results confirm that conjugation to $\mathrm{Ag}_{2} \mathrm{~S}$ QDs greatly enhances the hepatic targeting of NMN, which is translated into beneficial metabolic outcomes.

There was some indication that QD-NMN was having a greater effect on liver $\mathrm{NAD}^{+}$levels than $\mathrm{NMN}$ alone. This might explain the greater effect of QD-NMN than NMN alone on metabolic outcomes in the older mice. However, the difference in $\mathrm{NAD}^{+}$levels is not significant and raises the possibility that QD-NMN is influencing glucose and insulin metabolism via an additional mechanism that is independent of hepatocyte NAD levels. We previously found that fenestrations in the LSECs are the portal for the transfer of insulin from blood to hepatocytes. ${ }^{43}$ Loss of fenestrations occurs with old age, and this increases the barrier for the uptake of insulin and contributes to insulin resistance. $^{44}$ Moreover, we found that NMN can increase fenestrations and that drugs conjugated to $\mathrm{Ag}_{2} \mathrm{~S}$ QDs are actively endocytosed by the LSECs.

Therefore, the uptake of QD-NMN by LSECs might also improve insulin resistance in the liver by increasing fenestrations in these cells. We then studied the effect of QD-NMN on 
A. Autometallography silver staining
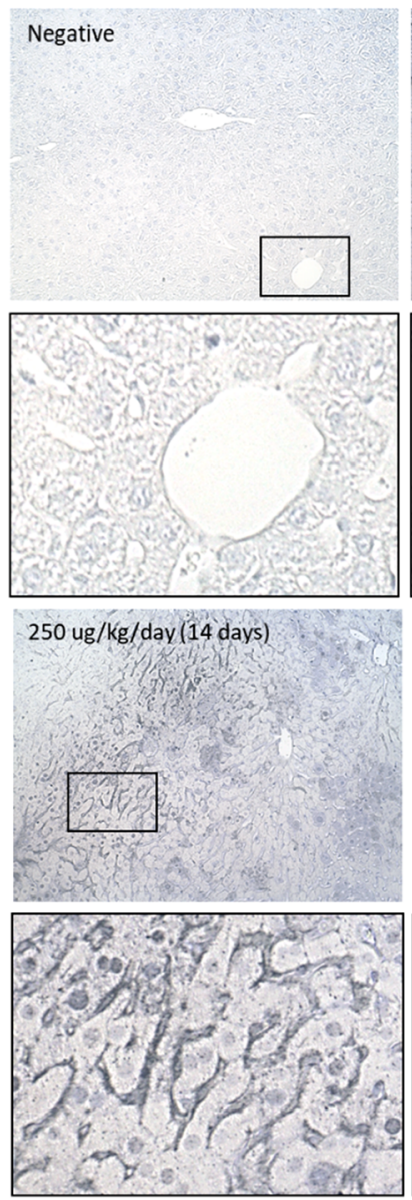

Liver
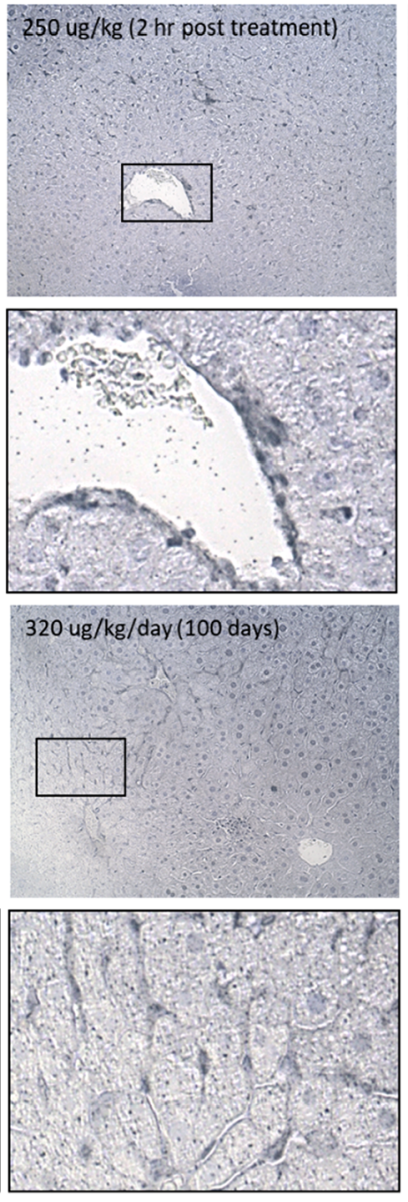
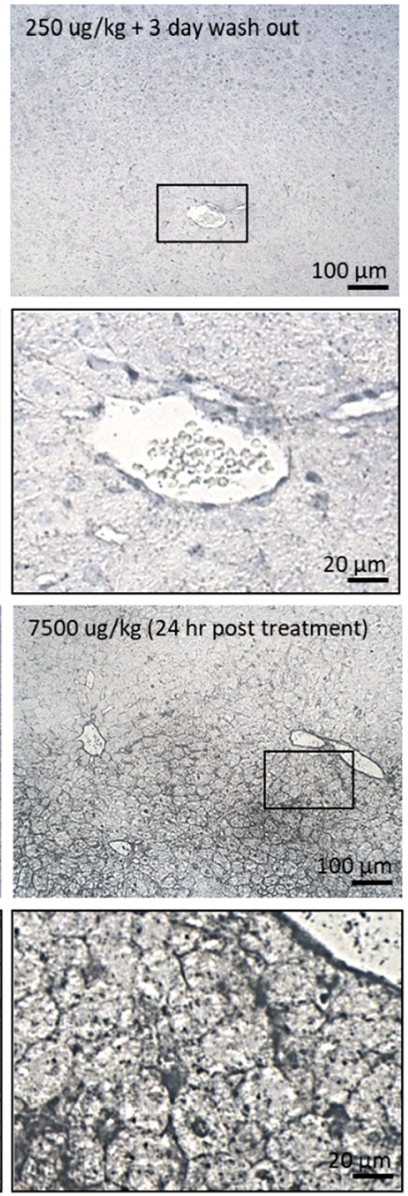

Small intestine

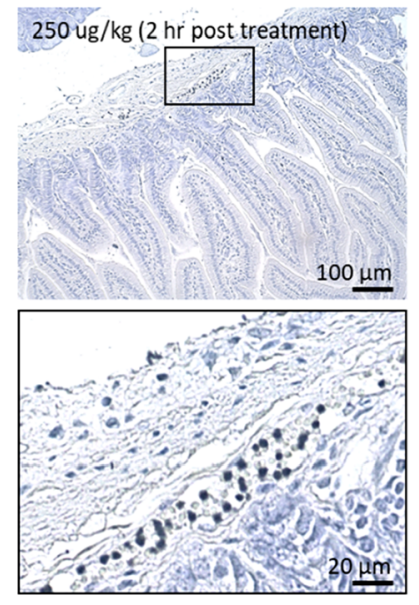

B. ICP.MS with outliner in 100 day

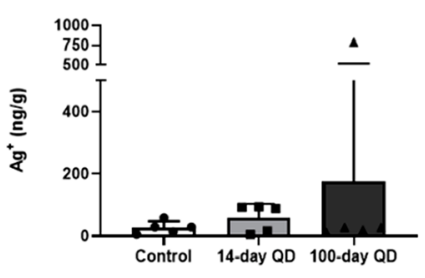

without outlier in 100 day

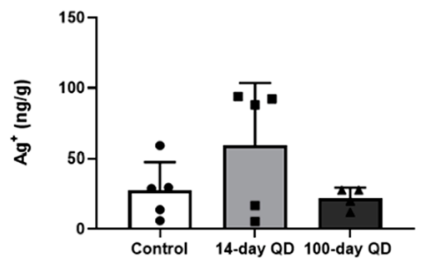

Figure 8. Autometallography staining of the liver and small intestine and inductively coupled plasma mass spectrometry. (A) Autometallography is a measure of silver distribution and involves adding additional silver to aggregate to silver ions in tissue sections. Liver panels show untreated negative control, $250 \mu \mathrm{g} / \mathrm{kg}$ treated, and $250 \mu \mathrm{g} / \mathrm{kg}$ treated with a 3 day wash out prior to tissue collection. Staining of the endothelium is absent in the 3 day wash out compared to the treated sample. Fourteen day $(250 \mu \mathrm{g} / \mathrm{kg} / \mathrm{day})$ and $100 \mathrm{day}(320 \mu \mathrm{g} / \mathrm{kg} / \mathrm{day})$ treated mice demonstrate staining in the sinusoids of the liver and of the bile ducts. The $7500 \mu \mathrm{g} / \mathrm{kg}$ (toxic dosage) shows silver staining in all tissue compartments with aggregates in hepatocytes. Small intestine panels show silver staining in the blood vessel underlining the villi. (B) ICP-MS was performed was performed on liver tissue samples to analysis the concentration of $\mathbf{A g}^{+}$. No differences were observed between groups, one 100 day sample demonstrated elevated $\mathrm{Ag}^{+}$content with data shown with and without outlier (statistical test: one-way ANOVA with post-hoc Bonferroni test); $\alpha=0.05$. Cells were then incubated with Alexa Fluor 488 goat anti-rabbit, $1 \%$ goat serum in PBS for 30 min at $4{ }^{\circ} \mathrm{C}$. Cells were again centrifuged, washed in PBS twice with centrifugation between washes.

fenestrations. Isolated LSECs were collected and treated with QD-NMN $(25 \mu \mathrm{g} / \mathrm{mL})$ and NMN $(250 \mu \mathrm{g} / \mathrm{mL})$. Scanning electron microscopy demonstrated both QD-NMN and NMN treatments increased the area covered by, and the number, of fenestrations (Supplementary Figure 8A-D). QD-NMN had a 3 -fold greater effect that NMN treatment with, NMN given at a 10 -fold dosage compared to QD-NMN. No overall differences in diameter were observed; however, a histogram of fenestration diameter demonstrated a shift toward larger fenestrations in NMN-treated cells (Supplementary Figure 8E).

Short- and Long-Term Toxicity of QDs and QD Drug Treatments. Short- and long-term toxicity was evaluated after $14(250 \mu \mathrm{g} / \mathrm{kg} /$ day $)$ and 100 days $(320 \mu \mathrm{g} / \mathrm{kg} /$ day $)$ of continuous treatment with QDs delivered via drinking water. There were no effects on AST or ALT levels, or liver, spleen, kidney, or small intestinal histology after 2 weeks treatment in mice aged 3, 18, or 24 months (Supplementary Figure 7).

One hundred days of continuous treatment was performed in mice aged 8-12 months. Mice demonstrated increased and sustained body weight growth during this period (Figure 7A). Long-term treatment did not lead to any significant changes in body weight or blood AST or ALT (Figure 7B). Histological examination only found minimal inflammatory cell infiltration after 100 days (Figure 7C). However, in subsequent investigations, there were no differences in liver TNF $\alpha$ expression or circulating IL-6 or IFN- $\gamma$ levels to suggest a sustained inflammatory response (Figure $7 \mathrm{D}, \mathrm{E}$ ). Neutrophil infiltration in the absence of a pro-inflammatory state was evaluated with MIP-2, ${ }^{45}$ and no changes in plasma levels were detected (Figure 7D). Within the liver and kidneys, there were no changes in the METAVIR fibrosis score, ${ }^{46,47}$ thickening of the glomeruli, or plasma creatinine between treated and untreated mice (Figure 7F,G). ${ }^{48}$ Overall, the data suggest that $320 \mu \mathrm{g} / \mathrm{kg} /$ day (100 days) $\mathrm{Ag}_{2} \mathrm{~S}$ QDs is not toxic, mostly likely as a result of rapid clearance by the liver. ${ }^{10}$ This was then further investigated.

$\mathrm{Ag}_{2} \mathrm{~S}$ and other QDs form a protein corona of basic circulating blood proteins including albumin, ${ }^{10,49}$ leading to less recog- 
nition by complement opsonization and immune cells compared to larger nanoparticles (in part due their smaller dynamic size $) ;{ }^{50,51}$ however, the trade-off of this is rapid clearance by the liver. ${ }^{52}$ This clearance of nanoparticles via non-Kupffer cell pathways over $72 \mathrm{~h}$ has been demonstrated by Poon et al. ${ }^{53}$ Uptake by Kupffer cells is understood to result in retention of nanoparticles with subsequent toxicity. ${ }^{53}$ To further examine the accumulation and clearance of QDs, autometallography of silver ${ }^{54}$ was performed on the liver following: untreated, $2 \mathrm{~h}$ after a single oral gavage of QDs $(250 \mu \mathrm{g} / \mathrm{kg}), 72 \mathrm{~h}$ after a single oral gavage of QDs $(250 \mu \mathrm{g} / \mathrm{kg}), 14$ day continuous treatment $(250$ $\mu \mathrm{g} / \mathrm{kg} /$ day $), 100$ day continuous treatment $(320 \mu \mathrm{g} / \mathrm{kg} /$ day $)$, $24 \mathrm{~h}$ after a single oral $7500 \mu \mathrm{g} / \mathrm{kg}$ gavage of QDs and small intestine $2 \mathrm{~h}$ after single oral gavage of QDs $(250 \mu \mathrm{g} / \mathrm{kg}$ ) (Figure $8)$. Silver was detected in all liver samples, excluding untreated mice, and was present in the blood vessels of the small intestine. We observed that following a 3 day wash out period, there was a reduction in silver staining in the endothelium in the liver (Figure 8A) and that there was no greater accumulation of silver in 14 versus 100 day treatments (Figure $8 \mathrm{~A}$ ), which indicates that the QDs are not accumulating and are being cleared from the liver. Staining in these continuous treatment samples was localized to the endothelium but not Kupffer cells and did not show aggregation in hepatocytes. Comparatively, high dosage and toxic treatment demonstrated aggregates within hepatocytes and a disrupted endothelium (Figure 8A).

To confirm this finding, inductively coupled plasma mass spectrometry (ICP-MS) was performed on liver samples from control, 14 day $(250 \mu \mathrm{g} / \mathrm{kg} /$ day $)$, and 100 day QD-treated mice $\left(320 \mu \mathrm{g} / \mathrm{kg} /\right.$ day). ICP-MS detection of $\mathrm{Ag}^{+}$ions was observed in low concentrations in both 14- and 100-day-treated samples compared to control or blank tissue samples (Figure $8 \mathrm{~B}$ ). Comparing 14 and 100 day liver samples, no differences in $\mathrm{Ag}^{+}$ ion content were observed. This supports the silver staining data shown in Figure 8A and demonstrates that the QDs are not accumulating within the liver over 14 or 100 day treatment and with no aggregation in Kupffer cells observed. Together this indicates that clearance is non-Kupffer cell mediated. ${ }^{6}$

Overall, previous nanoparticle toxicity studies, ${ }^{6}$ have demonstrated cellular necrosis, immune cell infiltration, increased inflammatory marker expression, oxidative stress, liver fibrosis, and impaired function of the liver and kidneys. We found no evidence for any such toxicity following 100 days of continuous treatment with $320 \mu \mathrm{g} / \mathrm{kg} /$ day QDs.

Clinical Relevance. Clinically, metformin is the first line treatment for type II diabetes mellitus and is currently under investigation for its therapeutic role in aging. ${ }^{55}$ Metformin is considered a safe and reliable medication in both the young and older population; taken as a therapeutic agent, it lowers blood glucose, improves insulin resistance, and promotes weight loss. ${ }^{55}$ Taken preventatively with lifestyle intervention, metformin reduces the incidence of type II diabetes mellitus. ${ }^{56}$ In the aging population, metformin outperforms and causes less harm in patients $>65$ years of age compared to alternative medications. ${ }^{57}$ However, there are limitations with metformin treatment. First, gastro-intestinal side effects develop in $25 \%$ of patients, with this directly related to high metformin concentrations in the intestine and liver. ${ }^{58}$ Excess lactate production mediates this side effect, with previous studies showing the intestine is the primary site of this lactate production (as reviewed in $\mathrm{McCreight}$ et al.). ${ }^{59}$ Second, metformin requires the OCT 1 transporter for both its intestinal and hepatic uptake with intolerance to metformin caused by polymorphisms in this transporter. ${ }^{58}$ This report also observed that intolerance to metformin (via impaired OCT1 uptake) also increases with age. QD-metformin may be a solution to these issues. QD-metformin has reduced intestinal availability and may reduce lactate and gastrointestinal discomfort in patients compared to metformin alone. QDmetformin does not require the OCT1 transporter for absorption by both intestinal and hepatic cells; therefore, intolerance and impaired uptake with aging may be overcome using our QD formulation.

The clinical effectiveness of NMN is an area of increasing interest, the receptor responsible for its uptake into cells has recently been reported; ${ }^{60}$ however, it is unclear if the effectiveness of NMN absorption and cellular uptake is reduced with aging. We have demonstrated that QD-NMN can outperform NMN alone in 24 month old mice and reverses age-associated HOMA insulin resistance with NMN treatment being ineffective over 2 weeks. We have, however, not shown its long-term benefit. The key effect of QD-NMN compared to NMN in this study is the activation of SIRT1 pathways in the liver endothelium in addition to hepatocytes. These cells facilitate the passive diffusion of glucose and insulin into the liver (a function reduced with increased age), this is not only critical for hepatic insulin sensitivity but preserving the liver microenvironment in aging and metabolic diseases. ${ }^{11,61}$ Finally, as QD-NMN is primarily targeted to the liver, it demonstrates that the metabolic functions of NMN are performed by the liver as proposed by Hunt et al. ${ }^{9}$

Future Directions. It has been proposed that biomedical research is at "the beginning of the end of the nanomedicine hype" primarily because of the lack of successful translation of nanomedicines for the treatment of cancer. ${ }^{62,63}$ However, the liver is an important therapeutic target for metabolic disorders and the aging process, and $80-95 \%$ of nanomaterials accumulate and are cleared in the liver. The success of nanomedicines will depend on directing research toward clinical problems. ${ }^{64}$ Nanomedicines hold considerable promise for targeting liver diseases and metabolic disorders regulated by the liver. ${ }^{65}$ The $\mathrm{Ag}_{2} \mathrm{~S}$ QDs in our study were very effective at enhancing oral bioavailability and hepatoselectivity of NMN and metformin with robust pharmacodynamic responses. QDs are an ideal candidate for nanotheranostics development. ${ }^{66}$ Nanotherapeutics that target the liver, rather than other sites, should be at the forefront of nanomedicine research.

\section{CONCLUSION}

$\mathrm{Ag}_{2} \mathrm{~S}$ QDs dramatically increased the hepatoselectivity of two pharmaceutical agents acting on AMPK and SIRT1 pathways: metformin and NMN. We have demonstrated that these QDs can be utilized as effective nanocarriers that (i) have greater biodistribution and selective uptake in the liver compared to the drug alone; (ii) utilize lower doses of the drug; (iii) have greater physiological effects at multiple time points post-treatment; (iv) bypass drug specific receptor uptake into hepatocytes, mitigating age-related decline in drug responses; (v) enhance the efficacy of treatment by regulating the local microenvironment via controlling the drug uptake in neighboring LSECs; and (vi) demonstrate negligible cellular toxicity, inflammation or tissue damage for at least 100 days of daily intake.

\section{EXPERIMENTAL PROCEDURES}

Ethics. The study was approved by the Animal Welfare Committee of the Sydney Local Health District and was performed in accordance with the Australian Code of Practice for the care and use of animals for 
scientific research (AWC approval: 2016/010 and 2018/010). All information provided accords with the ARRIVE guidelines.

Materials. Silver diethyldithiocarbamate (cat no. D93503, Merck, AUS), 1-dodecanethiol (cat no. 471364 Merck, AUS), cyclohexane (Merck, AUS), ethanol (Merck, AUS), xylene (Merck, AUS), acetone (Merck, AUS), $\mathrm{N}_{2}$ gas (BOC, AUS), Ar gas (BOC, AUS), 3mercaptopropionic acid [3-MPA] (cat no. M5801, Merek, AUS), metformin (cat no. D150959, Merck, AUS), nicotinamide mononucleotide (gift from Dr. Lindsay Wu, University of New South Wales, Australia), $\left({ }^{14} \mathrm{C}\right)$ metformin (cat no. MC-2023, Moravek, USA), $\left({ }^{3} \mathrm{H}\right)$ oleic acid (cat no. O-1518, Merck, AUS), N-(3-(dimethylamino)propyl)- $N^{\prime}$-ethyl carbodiimide hydrochloride [EDC] (cat no. E6383 Merek, AUS), N-hydroxysulfosuccinimide sodium salt [NHS] (cat no. 56485, Merek, AUS), SnakeSkin dialysis tubing 10,000 MWCO (cat no. 88243, ThermoFisher Scientific, AUS), scintillation fluid (Ultima Gold 2x, cat no. 6013329, PerkinElmer, AUS), $30 \% \mathrm{H}_{2} \mathrm{O}_{2}$ (cat no. 18312, Merck, AUS), solvable solution (cat no. 6NE9100, PerkinElmer, AUS), cytidine monophosphate (cat no. C1131, Merck, AUS), sucrose (cat no. S7903, Merck, AUS), omeprazole (cat no. O104, Merck, AUS), collagenase (type 1, cat no. 47D17410A, ProSciTech, AUS), RPMI1640 (Merek, AUS), DMEM (Merck, AUS), fetal calf serum (Merck, AUS), Percoll (Merek, AUS), penicillin-streptomycin (Merek, AUS), Whatman grade 4 filter paper (Merck, AUS), dimethyl sulfoxide (Merek, AUS), in vitro toxicology assay kit, MTT kit (cat no. TOX1$1 \mathrm{KT}$, Sigma-Aldrich, AUS), AST activity assay (cat no. MAK055, Merck, AUS), ALT activity assay (cat no. MAK052, Merck, AUS), creatinine assay kit (cat no. MAK080, Merck, AUS), IL-6 ELISA Kit, mouse (cat no. ab100712, Abcam, AUS), NAD/NADH quantification kit (cat no. MAK037, Merck, AUS), MIP-2/CXCL2Mouse ELISA kit (cat no. ab100727, Abcam, AUS), IFN gamma mouse ELISA kit (cat no. ab100689, Abcam, AUS), cyclic guanosine monophosphate ELISA kit (cat no. 581021, Sapphire Bioscience, AUS), cyclic guanosine monophosphate (cGMP) ELISA kit (cat no. 581021, Sapphire Bioscience, AUS), ultrasensitive mouse insulin ELISA kit (cat no. 80INSMSU-E01, ALPCO, USA), D-(+)-glucose (cat no. G7528, Merck, AUS), Accu-Chek Performa strips (cat no. p-4015630981946, Amcal, AUS), Accu-Chek Performa blood glucose meter kit (cat no. p4015630982219, Amcal, AUS), and insulin ELISA kit, mouse (cat no. 90080, Crystal Chem Inc., USA), SIRT1 antibody (cat no. 05-1243, Merck, AUS), TNF- $\alpha$ antibody (cat no. ab1793 Abcam, AUS), $p$-eNOS antibody (Ser1177, cat no. 9571, Genesearch, AUS), eNOS antibody (type 3, cat no. 610296, BD Bioscience, AUS), goat anti-rabbit IgG (H $+\mathrm{L}$ ) secondary antibody (cat no. 31460, ThermoFisher, AUS), 16-well Grace Bio-Laboratories CultureWell (cat no. GBL112358, Merck, AUS), $p$-AMPK $\alpha$ antibody (Thr172, cat no. 2531, Cell Signaling Technology, AUS), IRS-1 antibody (cat no. 2382, Cell Signaling Technology, AUS), IRS-2 antibody (cat no. 4502, Cell Signaling Technology, AUS), PCG-1 $\alpha$ antibody (cat no. 2178 , Cell Signaling Technology, AUS), AMPK $\alpha$ antibody (cat no. 2532, Australian Biosearch, AUS), Lyve1 antibody [EPR21771] (cat no. ab218535, Abcam, AUS), $\beta$-tubulin antibody (cat no. 2146, Cell Signaling Technology, AUS), Tom 20 antibody (cat no. 42406, Cell Signaling Technology, AUS), Alexa Fluor 488 goat anti-rabbit (cat no. R-37116; Thermo Fisher AUS). Western blot reagents were as follows: loading buffer (cat no. B0007, Thermo Fisher), running buffer (cat no. B0001, Thermo Fisher), transfer buffer (cat no. BT00061, Thermo Fisher), Ponceau staining (cat no. P7170, Sigma-Aldrich), Precision Plus Protein Western Standards (cat no. 1610376, BioRad, AUS), PBS tablets (cat no. P4417, Merck, AUS), Tween-20 (cat no. P1379, Merck, AUS), silver lactate (cat no. 359750, Merck, AUS), hydroquinone (cat no. H9003, Merck, AUS), sodium thiosulfate (cat no. 72049, Merck, AUS), and carboxymethyl cellulose (cat no. C4888, Merck, AUS).

Synthesis of Water-Soluble $\mathbf{A g}_{2} \mathrm{~S}$ QDs. $\mathrm{Ag}_{2} \mathrm{~S}$ QD synthesis has previously been reported. ${ }^{10,67}$ Briefly, $0.1 \mathrm{mM}$ silver diethyldithiocarbamate was mixed with $12 \mathrm{~mL}$ of 1-dodecanethiol under vigorous magnetic stirring. $\mathrm{A} \mathrm{N}_{2}$ vacuum was created followed by an $\mathrm{Ar}$ vacuum to remove oxygen from the mixture. The solution was heated to $200^{\circ} \mathrm{C}$ at a rate of $12{ }^{\circ} \mathrm{C} / \mathrm{min}$ and held at this temperature for $1 \mathrm{~h}$. Following synthesis, EtOH was added to the solution followed by centrifugation. $\mathrm{Ag}_{2} \mathrm{~S}$ QDs were resuspended in minimal cyclohexane, washed twice with $\mathrm{EtOH}$, with each wash resulting in precipitation of $\mathrm{Ag}_{2} \mathrm{~S}$ QDs and isolated with centrifugation. Aqueous phase transfer was performed with QDs suspended in a 1:1 ( v/v) mixture of cyclohexane and acetone under magnetic stirring. One milliliter of 3-mercaptopropionic acid was added per $25 \mathrm{mg}$ of $\mathrm{Ag}_{2} \mathrm{~S}$ QDs and mixed at room temperature for $1 \mathrm{~h}$. Following this, QDs were mixed with EtOH and centrifuged. The pellet was redispersed in minimal $\mathrm{MQ}$, washed with $\mathrm{EtOH}$ twice, and dispersed in MQ. Samples was then filtered using Whatman grade 4 filter paper. QDs were diluted to $10 \mathrm{mM}$ for storage at $4{ }^{\circ} \mathrm{C}$ in the dark.

Drug Attachment. Metformin and NMN were attached to $\mathrm{QDs}$ via EDC/NHS coupling. $\mathrm{Ag}_{2} \mathrm{~S}$ QD $(1 \mathrm{mM})$ was mixed with $1 \mathrm{mM}$ EDC and $1 \mathrm{mM}$ NHS in a reaction vial under heavy mixing for $1 \mathrm{~h}$. Following this, the $\mathrm{pH}$ was not altered for metformin or increased to $\mathrm{pH} 9$ with 1 $\mathrm{mM}$ (final volume) $\mathrm{Na}_{2} \mathrm{CO}_{3}$, and metformin or $\mathrm{NMN}$ was added to the solution. The solution was mixed overnight and transferred to dialysis tubing 10,000 MWCO and dialyzed with $1 \mathrm{~mL}$ solution per $1 \mathrm{~L}$ of MQ for 2,4 , and $16 \mathrm{~h}$ at $4{ }^{\circ} \mathrm{C}$ in the dark. Drug and QD-drug concentrations were determined using a Nanodrop UV-vis spectrophotometer for protein absorbance 205-280 nm (ThermoFisher, AUS).

Fourier Transform Infrared Microscopy. Confirmation of the deposition on QDs was performed using FTIR. FTIR was performed on a LUMOS FTIR microscope (Bruker, USA), at the vibrational spectrometry facilities at Sydney Analytical, the University of Sydney, Australia. Samples were collected from dried QD with a minimum of 10 measurements per material performed. Data show the average spectrum across $3500-700 \mathrm{~nm}$ in ATR mode, following atmosphere correction and normalization performed using OPUS 7.0 software (Bruker, USA). An average spectrum was produced from 10 to 20 individual measurements per material.

High-Voltage Transmission Electron Microscopy. Visualization of QDs from nonbiological samples was performed using high voltage transmission electron microscopy (HV-TEM). HV-TEM was performed on a JEOL 2100 (JEOL, AUS), at the transmission electron microscope facilities at the Australian Centre for Microscopy and Microanalysis, the University of Sydney, Australia. Nonbiological samples were prepared by evaporative deposition on carbon-based TEM grids.

Zetasizer Characterization. Hydrodynamic diameter, PDI, and zeta-potential were measured using a Zetasizer Nano ZS (Malvern Bioanalytical, AUS), at Sydney Analytical, the University of Sydney, Australia. Measurements were performed using $1 \mu \mathrm{M}$ QDs, QDmetformin or QD-NMN in MQ water. Hydrodynamic diameter size and PDI measurements were performed using backscatter $\left(173^{\circ}\right)$ data collection with three repeats of 12-15 measurements per sample. All samples were analyzed in disposable folded capillary cells. Zetapotential was measured with five repeats of 10-12 measurements per sample (maximal setting was 100 measurements). All data were collected with triplicate data points.

Mice. C57BL/6J 3-4 month old and 12 month old mice were obtained from the Animal Resource Centre in Perth, Western Australia. Animals were housed at the ANZAC Research Institute animal house on a $12 \mathrm{~h}$ light/dark cycle and provided with ad libitum access to food, water, and enrichment. Mice were aged under these conditions until 18 or 24 months of age.

Radiolabeling. Tritium: $10 \mathrm{mM}$ QDs were incubated at room temperature with $0.5 \mu \mathrm{Ci}\left({ }^{3} \mathrm{H}\right)$ oleic acid for $3 \mathrm{~h}$ in a sonication bath and $24 \mathrm{~h}$ under Ar gas with vigorous stirring. Removal of excess oleic acid was performed by two EtOH wash stages with centrifugation and redispersion in minimal MQ.

Carbon-14: $\left({ }^{14} \mathrm{C}\right)$ metformin was conjugated to QDs via EDC/NHS coupling. One $\mathrm{mM} \mathrm{Ag}_{2} \mathrm{~S}$ QD was mixed with $1 \mathrm{mM}$ EDC and $1 \mathrm{mM}$ NHS in a reaction vial under heavy mixing for $1 \mathrm{~h}$. Following this, the $\mathrm{pH}$ was not altered and $1.0 \mu \mathrm{Ci}\left({ }^{14} \mathrm{C}\right)$ metformin was added to the solution. The solution was mixed overnight and transferred to dialysis tubing 10,000 MWCO and dialyzed with $1 \mathrm{~mL}$ solution per $1 \mathrm{~L}$ of MQ for 2,4 , and $16 \mathrm{~h}$ at $4{ }^{\circ} \mathrm{C}$ in the dark.

Tissue Collection. Mice were not fasted prior to gavage of QDs with and without metformin or NMN for in vivo cellular mechanism or radioactive biodistribution studies (Figures 2 and 4). Gavage was performed using an esophageal gavage needle and delivered in a single 
rapid dose of $100 \mu \mathrm{L}$. Mice were euthanized by a single intraperitoneal injection of $100 \mathrm{mg} / \mathrm{kg}$ ketamine and $10 \mathrm{mg} / \mathrm{kg}$ xylazine following all experiments. Next, $200-250 \mathrm{mg}$ of tissue samples was collected from the liver, spleen, kidney, and small intestine along with $500 \mu \mathrm{L}$ of plasma blood collected via cardiac puncture. Tissue samples were snap frozen with liquid $\mathrm{N}_{2}$ or placed in $2.5 \%$ glutaraldehyde/4\% paraformaldehyde.

Sample Preparation and Radiolabeled Activity Analysis. Tissue samples were weighed and mixed in a reaction vial with $1 \mathrm{~mL}$ of solvable solution and incubated at $60{ }^{\circ} \mathrm{C}$ for $4 \mathrm{~h}$ to dissolve the tissue. Next, $0.2 \mathrm{~mL}$ of $30 \% \mathrm{H}_{2} \mathrm{O}_{2}$ was added to samples to reduce the dark color saturation. Samples were mixed with $10 \mathrm{~mL}$ of scintillation fluid. Radioactivity was measured using a scintillation counter (Tricarb 2100 TR, PerkinElmer, AUS). All samples were mixed with $10 \mathrm{~mL}$ of scintillation fluid (five measurements per sample). Baseline measurements were collected from control mice that were not treated with radioactive QDs. Data were collected as disintegrations per minute and used for analysis. All radioactivity data presented in this article used $n=$ 3 mice per group for in vitro hepatocyte endocytosis, and the experiments were performed in triplicate.

Hepatocyte and LSEC Isolation. The isolation of hepatocytes and LSECs has previous been reported in our methods paper and our previous studies. ${ }^{17,68,69}$ In brief, mice were anesthetized with a mixture of $10 \mathrm{mg} / \mathrm{kg}$ xylazine and $100 \mathrm{mg} / \mathrm{kg}$ ketamine with liver cannulated via the portal vein and perfused with Krebs buffer solution $(0.142 \mathrm{M} \mathrm{NaCl}$, $6.71 \mathrm{mM} \mathrm{KCl}, 9.63 \mathrm{mM}$ HEPES, and $4.6 \mathrm{mM} \mathrm{CaCl}_{2}$ ) and collagenase at $37^{\circ} \mathrm{C}$. The liver was removed and dissociated by forceps in Krebs buffer solution (without $\mathrm{CaCl}_{2}$ ) at $4{ }^{\circ} \mathrm{C}$. Cells filtered and collected in Krebs buffer solution (without $\mathrm{CaCl}_{2}$ but with $10 \mathrm{~g} / \mathrm{L}$ BSA). All centrifugation steps, including the Percoll gradients, were performed at $4{ }^{\circ} \mathrm{C}$. Hepatocytes were isolated by three $10 \mathrm{~min}$ centrifugations at $50 \mathrm{~g}$. Dead cells were removed by collecting the fraction between a two-step Percoll gradient $(40 \%, 50 \%)$. LSECs were collected from the hepatocyte supernatant and isolated using another two-step Percoll gradient $(25 \%$, $45 \%$ ) and centrifugation at $1350 \mathrm{~g}$. Kupffer cells were removed from the LSEC fraction by selective adherence to plastic using two $8 \mathrm{~min}$ incubations at $37^{\circ} \mathrm{C}$ in RPMI media. Cells were cultivated in serum free RPMI- 1640 media at $0.2 \times 10^{6} \mathrm{cells} / \mathrm{cm}^{2}$ on fibronectin-coated 16 -well chambered \#1.5 coverslips at $37^{\circ} \mathrm{C}$ prior to use; however, they were not stored $>4 \mathrm{~h}$ prior to use. Cells were suspended in PBS followed by cell counting, centrifuged, and prepared for either Western blots, assays, or in vitro experimentation as described below.

Flow Cytometry. Purity of cell cultures was performed on a BD LSR Fortessa X-20 flow cytometer (BD Biosciences, AUS) with data analyzed on FlowJo (v20, FlowJo LLC, ON, USA). LSEC cell culture purity $(90 \%)$ was assessed using fluorescent marker staining. Following cell isolation methods, LSECs were washed in PBS, centrifuged ( $1350 \mathrm{~g}$, $10 \mathrm{~min}, 4{ }^{\circ} \mathrm{C}$ ), and incubated with anti-Lyve-1 primary antibody $(1: 100)$ or rabbit $\operatorname{IgG}(1: 100)$ and $1 \%$ goat serum in PBS for $30 \mathrm{~min}$ at 4 ${ }^{\circ} \mathrm{C}$. Cells were centrifuged and washed in PBS twice with centrifugation between washes.

Hepatocytes cell culture purity (95\%) were analyzed based on size criteria and based on autofluorescence. Fifty thousand events were collected per dilution, with events limited to size criteria. Results show the sample data with linear and $\log _{10}$ scale ungated or following size execution with 488 signal and 730 signals. All flow cytometry data in Supplementary Figure 9 used $n=5$ measurements.

Western B lots. Western blots were performed on isolated hepatocytes and LSEC cells $2 \mathrm{~h}$ after gavage with QDs or QDmetformin, QD-NMN, or untreated controls. Western blots were also performed on in vitro-treated SK-Hep1 cells following $2 \mathrm{~h}$ treatment with QDs or QD-metformin, QD-NMN, or untreated controls. Cells were lysed using a Polytron homogenizer (PT1200E, Kinematica, Germany) with total protein extracted as previously described. ${ }^{69}$ Bolt tris-bis plus gels were run with negative control blank wells and positive control samples known to contain the protein of interest. After transfer, the PVDF membrane was incubated with primary antibodies to $p$ AMPK, AMPK, SIRT1, peNOS, NOS, IRS-1, IRS-2, PCG-1 $\alpha$, Tom20, and $\beta$-tubulin, followed by incubation with secondary antibody and developed using ECL-Plus chemiluminescence detection solution. Each membrane was analyzed per protein, striped, and stained for the $\beta$ - tubulin. Image data were collected using Image Lab 6.1 software (BioRad, USA) with protein $\mathrm{kDa}$ determined using the automated software in Image Lab software (BioRad, USA). Both the known protein $\mathrm{kDa}$ and ladder type are used by the imaging software to determine the band for analysis. Densitometry measurements were performed using ImageJ software (NIH, USA). Protein expression was normalized based on $\beta$-tubulin. Mean \pm SD was calculated from 3 to 5 individual experiments.

Assays for Hepatocyte Metabolites. Assays for cGMP, NAD/ $\mathrm{NADH}$, and MTT were performed using commercial kits as per their instructions. Sample preparation buffers were provided in cGMP and $\mathrm{NAD} / \mathrm{NADH}$ kits with tissue and cells prepared using a Polytron homogenizer, centrifugation, and analysis of the supernatant. Analysis of cGMP and $\mathrm{NAD} / \mathrm{NADH}$ in vitro-treated cells was performed using sample preparation buffers and cells collected via cell scraper. Samples were centrifuged with supernatant analyzed. MTT assays were performed per instructions with incubation with MTT reagent and cell lysis/color development with DMSO.

Assays for Toxicity and Immune Response. Assays for ALT, AST, IL-6, MIP-2, IFN- $\gamma$, and creatinine were performed using commercial kits per their instructions. Sample preparation buffers were provided in kits with plasma samples were analyzed without additional steps. Assays were performed in triplicate.

Cell Culture. The human SK-Hep1 cells were obtained from the American Type Tissue Culture Collection (ATCC, USA) and were cultured in a humidified $5 \% \mathrm{CO}_{2}$ incubator at $37^{\circ} \mathrm{C}$. Cells were grown in DMEM supplemented with $10 \%$ fetal calf serum and penicillinstreptomycin. SK-Hep1 cells were starved for $4 \mathrm{~h}$ by removing FCS from DMEM media. Cells were treated with $0.1 \mathrm{ng} / \mathrm{mL}$ QDs, QDmetformin $(0.1$ and $1.6 \mathrm{ng} / \mathrm{mL})$, and QD-NMN 0.1 and $3.2 \mathrm{ng} / \mathrm{mL}$ for $2 \mathrm{~h}$ prior to Western blot experimentation.

In Vitro Hepatocyte Endocytosis and NAD Generation. Endocytosis assays of $\left({ }^{3} \mathrm{H}\right) \mathrm{QD} s,\left({ }^{14} \mathrm{C}\right)$ metformin, and QD- $\left({ }^{14} \mathrm{C}\right)$ metformin uptake and NAD generation were performed using isolated hepatocytes from young and old mice. Cells were plated at $0.25 \times 10^{6}$ cells in a 24-well plate with RPMI media. Cells were washed $2 \mathrm{~h}$ after plating and incubated for $2 \mathrm{~h}$ before use. Cells were either untreated or pretreated with inhibitors of (1) clathrin-mediated and micropinocytosis endocytic pathways (sucrose; $0.5 \mathrm{M}, 30 \mathrm{~min}$ ), (2) cell membrane protein pumps (omeprazole; $10 \mu \mathrm{M}, 30 \mathrm{~min}$ ), and (3) phosphorylation competitive inhibitor (cytidine monophosphate; 2 $\mathrm{mM}, 1 \mathrm{~h})$ in serum-free RPMI-1640 media. Hepatocytes were then incubated with either $300 \mu \mathrm{L}$ of $\left({ }^{3} \mathrm{H}\right) \mathrm{QDs},\left({ }^{14} \mathrm{C}\right)$ metformin, and QD$\left({ }^{14} \mathrm{C}\right)$ metformin in DMPI without phenol red or $300 \mu \mathrm{L}$ NMN or QDNMN for 2 h at $37^{\circ} \mathrm{C}$

For analysis of endocytosis of radiolabeled substrates, two fractions were collected: cell media and lysed cells. Cells were lysed with $0.1 \%$ SDS solution and collected using a cell scraper. Radioactivity was measured using a scintillation counter (Tricarb 2100 TR, PerkinElmer, AUS). The proportion of radiation relative to the total injectate is shown. All radioactivity studies were performed in triplicate. For analysis of NAD generation, following QD-NMN or NMN treatment for $2 \mathrm{~h}$, cells were washed with $\mathrm{PBS}$ and lysed with NAD extraction buffer per NAD/NADH kit instructions. Samples were then prepared as described in the assay section. Studies were performed in triplicate.

LSEC Fenestration Ultrastructure Imaging. The in vitro effects of NMN and QD-NMN on fenestrations were evaluated using scanning electron microscopy (SEM). SEM and analysis were performed as previous described, ${ }^{17}$ using a JEOL 6380 scanning electron microscope (JEOL Ltd., AUS). Images were collected at 10,000× magnification. Image analysis was performed by a blinded observer using ImageJ (NIH, USA). Between 1094 and 1272 fenestrations were counted per treatment. Fenestrations less than $30 \mathrm{~nm}$ and gaps more than $300 \mathrm{~nm}$ were excluded from the analysis. Porosity was defined as the percentage of the cell membrane covered with fenestrations. Frequency was defined as the number of fenestrations per $1 \mu \mathrm{m}^{2}$.

Oral Glucose Tolerance Testing and Insulin Levels. oGTTs were performed following a $4 \mathrm{~h}$ fast in young and old mice. Blood glucose was measured used a hand-held glucometer using Accu-check proforma strips. Blood was collected by tail vein sampling following a 
tail snip. Blood glucose was collected $-15,0,15,30,45,60$, and 90 min after an oral bolus of $2 \mathrm{~g} / \mathrm{kg}$ glucose solution. Insulin was measured using an ultrasensitive mouse insulin ELISA kit according to the manufacturer's instructions. Ten microliters of blood was collected following a $4 \mathrm{~h}$ fast $(-15 \mathrm{~min})$ and after an oral bolus of $2 \mathrm{~g} / \mathrm{kg}$ glucose solution (15 min).

Administration of Drugs in Drinking Water. Drinking water was spiked with QD, QD-NMN, and NMN. Dosages were determined based on the daily water intake and weight of the mice. Dosages used were as follows: QD $(250 \mu \mathrm{g} / \mathrm{kg})$, QD-NMN $(250 \mu \mathrm{g} / \mathrm{kg}$ and $8 \mathrm{mg} /$ $\mathrm{kg})$, and NMN $(800 \mathrm{mg} / \mathrm{kg})$.

Histology and Immunofluorescence. The $4 \%$ paraformaldehyde fixed samples were processed using a Tissue Tek VIP 6AI tissue processor (Sakura Finetek, USA) and embedded in wax. Sections were cut on a microtome and mounted on Superfrost slides. H\&E and Sirius Red staining were performed as previously described. ${ }^{70}$ Immunofluorescence for TNF $\alpha$ (1:100) was performed following blocking and conjugated with anti-rabbit secondary antibody. Nuclei were visualized with Hoechst 33342. Imaging was performed on either a Leica SP8 (Leica Microsystems, AUS) or an EVOS FL Auto 2 (ThermoFisher, AUS). Image preparation was performed using SlideBook software (Leica Microsystems, AUS) and ImageJ software (NIH, USA).

Liver fibrosis was quantified based on METAVIR scoring: ${ }^{46,47} 0$, no fibrosis; 1 , mild fibrosis of the portal veins; 2 , fibrotic septae between portal veins; 3 , fibrotic septae between portal and central vein; 4 , cirrhosis.

Autometallography Staining. Autometallography staining was performed as previously described. ${ }^{71}$ In brief, glassware was cleaned for $48 \mathrm{~h}$ prior using Farmer solution (10\% sodium thiosulfate, 10\% potassium ferricyanide); deparaffinized and hydrated sections were incubated at for $90 \mathrm{~min}$ at $26^{\circ} \mathrm{C}$ with autometallography developer solution ( $1.2 \%$ carboxymethylcellulose, $9.2 \mathrm{mg} / \mathrm{mL}$ hydroquinone, 9 $\mathrm{mg} / \mathrm{mL}$ silver lactate, in citrate buffer $\mathrm{pH} 3.8$ ). Slides were washed with $5 \%$ sodium thiosulfate and counterstained with hematoxylin.

Inductively Coupled Plasma Mass Spectrometry. Seventy-five milligram liver samples were collected from control (100-day toxicity controls $), 14$ day $(250 \mu \mathrm{g} / \mathrm{kg} /$ day $)$, and 100 day $(320 \mu \mathrm{g} / \mathrm{kg} / \mathrm{day}) \mathrm{QD}-$ treated mice ( $n=5$ per group). Samples were dissolved in $>90 \%$ nitric acid at room temperature overnight. Solutions were diluted to $1 \%$ nitric acid with MQ and centrifuged to remove precipitated protein, and supernatants were collected for elemental analysis using ICP-MS (NexION 2000, PerkinElmer, USA) fitted with a glass cyclonic spray chamber. Multielement standard solution was used for calibration of $\mathrm{Ag}$, and $\mathrm{Rh}$ was used as internal standard. The dwell time for ${ }^{103} \mathrm{Rh}$ measurement was 50 and $500 \mathrm{~ms}$ for ${ }^{107} \mathrm{Ag}$, and 20 sweeps per reading, one reading per replicate and three replicates were performed for each sample. Detection limit for Ag was 0.054 ppt. Syngistix for ICP-MS software was used for data collection and processing.

Statistics. All statistical analysis was performed using KruskalWallis tests with a post-hoc Dunn's method ( $n=3$ experiments) or oneway ANOVA with post-hoc Bonferroni test ( $n=5$ experiments); posthoc methods were applied for comparison between multiple groups (GraphPad Prism 8.4.0, GraphPad Software, Inc., USA). Power calculations were performed as previously described. ${ }^{72}$ All data presented in Figure 1 are expressed as mean \pm SD $(n=3)$; data in Figures $2-8$ are expressed in mean \pm SD; Figures $2-5$ are $n=3$, and Figures $6-8$ are $n=5$.

\section{ASSOCIATED CONTENT}

\section{(1) Supporting Information}

The Supporting Information is available free of charge at https://pubs.acs.org/doi/10.1021/acsnano.0c09278. The raw data are available upon request to the corresponding author.

Expanded DLS data, Western blot images, expanded 2 week treatment and histology, fenestration data and cell culture purity data (PDF)

\section{AUTHOR INFORMATION}

\section{Corresponding Author}

Victoria C. Cogger - Ageing and Alzheimers Institute, Centre for Education \& Research on Ageing, Concord Repatriation General Hospital, ANZAC Research Institute, Concord, NSW 2139, Australia; Faculty of Medicine and Health and Charles Perkins Centre, The University of Sydney, Sydney, NSW 2006, Australia; (1) orcid.org/0000-0002-6346-9928;

Email: victoria.cogger@sydney.edu.au

\section{Authors}

Nicholas J. Hunt - Ageing and Alzheimers Institute, Centre for Education \& Research on Ageing, Concord Repatriation General Hospital, ANZAC Research Institute, Concord, NSW 2139, Australia; Faculty of Medicine and Health, Charles Perkins Centre, and Sydney Nano Institute, The University of

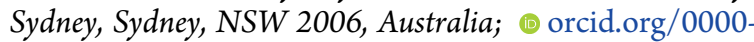
0002-9001-0602

Glen P. Lockwood - Ageing and Alzheimers Institute, Centre for Education \& Research on Ageing, Concord Repatriation General Hospital, ANZAC Research Institute, Concord, NSW 2139, Australia; Faculty of Medicine and Health, The University of Sydney, Sydney, NSW 2006, Australia

Sun W. S. Kang - Ageing and Alzheimers Institute, Centre for Education \& Research on Ageing, Concord Repatriation General Hospital, ANZAC Research Institute, Concord, NSW 2139, Australia; Cell Biology and Imaging Section, Thoracic and Gastrointestinal Oncology Branch, National Cancer Institute, National Institutes of Health, Bethesda, Maryland 20892, United States

Lara J. Westwood - Faculty of Science, University of Technology Sydney, Sydney, NSW 2000, Australia

Christina Limantoro - Sydney Nano Institute, The University of Sydney, Sydney, NSW 2006, Australia; Sydney Pharmacy School, Faculty of Medicine and Health, The University of Sydney, Sydney, NSW 2006, Australia

Wojciech Chrzanowski - Sydney Nano Institute, The University of Sydney, Sydney, NSW 2006, Australia; Sydney Pharmacy School, Faculty of Medicine and Health, The University of Sydney, Sydney, NSW 2006, Australia

Peter A. G. McCourt - Charles Perkins Centre, The University of Sydney, Sydney, NSW 2006, Australia; Department of Medical Biology, University of Tromsø - The Arctic University of Norway, Tromsø 9037, Norway

Zdenka Kuncic - Charles Perkins Centre and Sydney Nano Institute, The University of Sydney, Sydney, NSW 2006, Australia; School of Physics, The University of Sydney, Sydney, NSW 2006, Australia

David G. Le Couteur - Ageing and Alzheimers Institute, Centre for Education \& Research on Ageing, Concord Repatriation General Hospital, ANZAC Research Institute, Concord, NSW 2139, Australia; Faculty of Medicine and Health and Charles Perkins Centre, The University of Sydney, Sydney, NSW 2006, Australia

Complete contact information is available at: https://pubs.acs.org/10.1021/acsnano.0c09278

\section{Author Contributions}

Study concept: V.C., D.L.C., Z.K., P.G., N.H. Experimentation: N.H., G.L., S.K., L.W., C.L., W.C.. Figures: N.H. Manuscript: N.H., V.C., D.L.C., Z.K., P.G. 


\section{Notes}

The authors declare no competing financial interest.

\section{ACKNOWLEDGMENTS}

NHMRC project Grant No. 1141234; Sydney Medical School Foundation McKnight Bequest, The University of Sydney DVCR Research Equity Fellowship, The University of Sydney Seed Grant and the University of Tromsø Faculty of Health Sciences travel grant to P.M. Australian Centre for Microscopy and Microanalysis and the Sydney Analytical Vibrational Spectrometry Facility, the University of Sydney. The Microscopy and Flow Cytometry Core Facility, ANZAC Research Institute. Concord RG Hospital Electron Microscopy Unit.

\section{REFERENCES}

(1) Zrazhevskiy, P.; Gao, X. Multifunctional Quantum Dots for Personalized Medicine. Nano Today 2009, 4 (5), 414-428.

(2) Wagner, A. M.; Knipe, J. M.; Orive, G.; Peppas, N. A. Quantum Dots in Biomedical Applications. Acta Biomater. 2019, 94, 44-63.

(3) Pelaz, B.; Alexiou, C.; Alvarez-Puebla, R. A.; Alves, F.; Andrews, A. M.; Ashraf, S.; Balogh, L. P.; Ballerini, L.; Bestetti, A.; Brendel, C.; Bosi, S.; Carril, M.; Chan, W. C. W.; Chen, C.; Chen, X.; Chen, X.; Cheng, Z.; Cui, D.; Du, J.; Dullin, C.; et al. Diverse Applications of Nanomedicine. ACS Nano 2017, 11 (3), 2313-2381.

(4) Hassan, S.; Prakash, G.; Bal Ozturk, A.; Saghazadeh, S.; Farhan Sohail, M.; Seo, J.; Remzi Dokmeci, M.; Zhang, Y. S.; Khademhosseini, A. Evolution and Clinical Translation of Drug Delivery Nanomaterials. Nano Today 2017, 15, 91-106.

(5) Tsoi, K. M.; MacParland, S. A.; Ma, X.-Z.; Spetzler, V. N.; Echeverri, J.; Ouyang, B.; Fadel, S. M.; Sykes, E. A.; Goldaracena, N.; Kaths, J. M.; Conneely, J. B.; Alman, B. A.; Selzner, M.; Ostrowski, M. A.; Adeyi, O. A.; Zilman, A.; McGilvray, I. D.; Chan, W. C. W. Mechanism of Hard-Nanomaterial Clearance by the Liver. Nat. Mater. 2016, 15 (11), 1212-1221.

(6) Kermanizadeh, A.; Powell, L. G.; Stone, V. A Review of Hepatic Nanotoxicology - Summation of Recent Findings and Considerations for the Next Generation of Study Designs. J. Toxicol. Environ. Health, Part B 2020, 23 (4), 137-176.

(7) Kim, H. J.; Kim, A.; Miyata, K.; Kataoka, K. Recent Progress in Development of siRNA Delivery Vehicles for Cancer Therapy. Adv. Drug Delivery Rev. 2016, 104, 61-77.

(8) Murakami, M.; Nishina, K.; Watanabe, C.; Yoshida-Tanaka, K.; Piao, W.; Kuwahara, H.; Horikiri, Y.; Miyata, K.; Nishiyama, N.; Kataoka, K.; Yoshida, M.; Mizusawa, H.; Yokota, T. Enteral siRNA Delivery Technique for Therapeutic Gene Silencing in the Liver via the Lymphatic Route. Sci. Rep. 2015, 5 (1), 17035.

(9) Hunt, N. J.; McCourt, P. A. G.; Le Couteur, D. G.; Cogger, V. C. Novel Targets for Delaying Aging: The Importance of the Liver and Advances in Drug Delivery. Adv. Drug Delivery Rev. 2018, 135, 39-49.

(10) Hunt, N. J.; Lockwood, G. P.; Le Couteur, F. H.; McCourt, P. A. G.; Singla, N.; Kang, S. W. S.; Burgess, A.; Kuncic, Z.; Le Couteur, D. G.; Cogger, V. C. Rapid Intestinal Uptake and Targeted Delivery to the Liver Endothelium Using Orally Administered Silver Sulfide Quantum Dots. ACS Nano 2020, 14 (2), 1492-1507.

(11) Hunt, N. J.; Kang, S. W.; Lockwood, G. P.; Le Couteur, D. G.; Cogger, V. C. Hallmarks of Aging in the Liver. Comput. Struct. Biotechnol. J. 2019, 17, 1151-1161.

(12) Alfaras, I.; Mitchell, S. J.; Mora, H.; Lugo, D. R.; Warren, A.; Navas-Enamorado, I.; Hoffmann, V.; Hine, C.; Mitchell, J. R.; Le Couteur, D. G.; Cogger, V. C.; Bernier, M.; de Cabo, R. Health Benefits of Late-Onset Metformin Treatment Every Other Week in Mice. npj Aging Mech Dis 2017, 3 (1), 16.

(13) Katsyuba, E.; Romani, M.; Hofer, D.; Auwerx, J. NAD ${ }^{+}$ Homeostasis in Health and Disease. Nat. Metab 2020, 2, 9.

(14) Mills, K. F.; Yoshida, S.; Stein, L. R.; Grozio, A.; Kubota, S.; Sasaki, Y.; Redpath, P.; Migaud, M. E.; Apte, R. S.; Uchida, K.; Yoshino, J.; Imai, S.-i. Long-Term Administration of Nicotinamide Mono- nucleotide Mitigates Age-Associated Physiological Decline in Mice. Cell Metab. 2016, 24 (6), 795-806.

(15) Yoshino, J.; Mills, K. F.; Yoon, M. J.; Imai, S.-I. Nicotinamide Mononucleotide, a Key $\mathrm{NAD}^{+}$Intermediate, Treats the Pathophysiology of Diet-and Age-Induced Diabetes in Mice. Cell Metab. 2011, 14 (4), 528-536.

(16) Hunt, N. J.; Lockwood, G. P.; Kang, S. W.; Pulpitel, T.; Clark, X.; Mao, H.; McCourt, P. A.; Cooney, G. J.; Wali, J. A.; Le Couteur, F. H. The Effects of Metformin on Age-Related Changes in the Liver Sinusoidal Endothelial Cell. J. Gerontol A Biol. Sci. 2020, 75 (2), 278285.

(17) Hunt, N. J.; Lockwood, G. P.; Warren, A.; Mao, H.; McCourt, P. A.; Le Couteur, D. G.; Cogger, V. C. Manipulating Fenestrations in Young and Old Liver Sinusoidal Endothelial Cells. Am. J. Physiol Gastrointest Liver Physiol 2019, 316 (1), G144-G154.

(18) Patiño-Herrera, R.; Louvier-Hernández, J. F.; Escamilla-Silva, E. M.; Chaumel, J.; Escobedo, A. G. P.; Pérez, E. Prolonged Release of Metformin by $\mathrm{SiO}_{2}$ Nanoparticles Pellets for Type II Diabetes Control. Eur. J. Pharm. Sci. 2019, 131, 1-8.

(19) Xu, H.; Jiang, Q.; Reddy, N.; Yang, Y. Hollow Nanoparticles from Zein for Potential Medical Applications. J. Mater. Chem. 2011, 21 (45), 18227-18235.

(20) Pereira, A.; Brito, G.; Lima, M.; Silva Junior, A.; Silva, E.; de Rezende, A.; Bortolin, R.; Galvan, M.; Pirih, F.; Araujo Junior, R.; Medeiros, C.; Guerra, G.; Araujo, A. Metformin Hydrochloride-Loaded PLGA Nanoparticle in Periodontal Disease Experimental Model Using Diabetic Rats. Int. J. Mol. Sci. 2018, 19 (11), 3488.

(21) Panda, B. P.; Krishnamoorthy, R.; Shivashekaregowda, N. K. H.; Patnaik, S. Influence of Poloxamer- 188 on Design and Development of Second Generation PLGA Nanocrystals of Metformin Hydrochloride. Nano Biomed. Eng. 2018, 10 (4), 334-343.

(22) Kumar, S.; Bhanjana, G.; Verma, R. K.; Dhingra, D.; Dilbaghi, N.; Kim, K. H. Metformin-Loaded Alginate Nanoparticles as an Effective Antidiabetic Agent for Controlled Drug Release. J. Pharm. Pharmacol. 2017, 69 (2), 143-150.

(23) Chinnaiyan, S. K.; Karthikeyan, D.; Gadela, V. R. Development and Characterization of Metformin Loaded Pectin Nanoparticles for T2 Diabetes Mellitus. Pharm. Nanotechnol. 2019, 6 (4), 253-263.

(24) Jose, P.; Sundar, K.; Anjali, C.; Ravindran, A. Metformin-Loaded Bsa Nanoparticles in Cancer Therapy: A New Perspective for an Old Antidiabetic Drug. Cell Biochem. Biophys. 2015, 71 (2), 627-636.

(25) Choi, Y. H.; Han, H.-K. Nanomedicines: Current Status and Future Perspectives in Aspect of Drug Delivery and Pharmacokinetics. J. Pharm. Invest. 2018, 48 (1), 43-60.

(26) Sambol, N. C.; Chiang, J.; O'Conner, M.; Liu, C. Y.; Lin, E. T.; Goodman, A. M.; Benet, L. Z.; Karam, J. H. Pharmacokinetics and Pharmacodynamics of Metformin in Healthy Subjects and Patients with Noninsulin-Dependent Diabetes Mellitus. J. Clin. Pharmacol. 1996, 36 (11), 1012-1021.

(27) Padwal, R. S.; Gabr, R. Q.; Sharma, A. M.; Langkaas, L.-A.; Birch, D. W.; Karmali, S.; Brocks, D. R. Effect of Gastric Bypass Surgery on the Absorption and Bioavailability of Metformin. Diabetes Care 2011, 34 (6), 1295-1300.

(28) Isin, E. M.; Guengerich, F. P. Complex Reactions Catalyzed by Cytochrome P450 Enzymes. Biochim. Biophys. Acta, Gen. Subj. 2007, 1770 (3), 314-329.

(29) Bobo, D.; Robinson, K. J.; Islam, J.; Thurecht, K. J.; Corrie, S. R. Nanoparticle-Based Medicines: A Review of FDA-Approved Materials and Clinical Trials to Date. Pharm. Res. 2016, 33 (10), 2373-2387.

(30) Boles, M. A.; Ling, D.; Hyeon, T.; Talapin, D. V. The Surface Science of Nanocrystals. Nat. Mater. 2016, 15 (2), 141-153.

(31) Gao, L.; Liu, G.; Ma, J.; Wang, X.; Zhou, L.; Li, X. Drug Nanocrystals: In Vivo Performances. J. Controlled Release 2012, 160 (3), 418-430.

(32) Szunerits, S.; Melinte, S.; Barras, A.; Pagneux, Q.; Voronova, A.; Abderrahmani, A.; Boukherroub, R. The Impact of Chemical Engineering and Technological Advances on Managing Diabetes: Present and Future Concepts. Chem. Soc. Rev. 2020, DOI: 10.1039/ C9CS00886A. 
(33) Patel, S.; Kim, J.; Herrera, M.; Mukherjee, A.; Kabanov, A. V.; Sahay, G. Brief Update on Endocytosis of Nanomedicines. Adv. Drug Delivery Rev. 2019, 144, 90-111.

(34) Behzadi, S.; Serpooshan, V.; Tao, W.; Hamaly, M. A.; Alkawareek, M. Y.; Dreaden, E. C.; Brown, D.; Alkilany, A. M.; Farokhzad, O. C.; Mahmoudi, M. Cellular Uptake of Nanoparticles: Journey inside the Cell. Chem. Soc. Rev. 2017, 46 (14), 4218-4244.

(35) Rosario, D.; Benfeitas, R.; Bidkhori, G.; Zhang, C.; Uhlen, M.; Shoaie, S.; Mardinoglu, A. Understanding the Representative Gut Microbiota Dysbiosis in Metformin-Treated Type 2 Diabetes Patients Using Genome-Scale Metabolic Modeling. Front Physiol 2018, 9, 775.

(36) Nies, A. T.; Hofmann, U.; Resch, C.; Schaeffeler, E.; Rius, M.; Schwab, M. Proton Pump Inhibitors Inhibit Metformin Uptake by Organic Cation Transporters (OCTs). PLoS One 2011, 6 (7), e22163.

(37) Dong, S.; Cho, H. J.; Lee, Y. W.; Roman, M. Synthesis and Cellular Uptake of Folic Acid-Conjugated Cellulose Nanocrystals for Cancer Targeting. Biomacromolecules 2014, 15 (5), 1560-1567.

(38) Anas, A.; Okuda, T.; Kawashima, N.; Nakayama, K.; Itoh, T.; Ishikawa, M.; Biju, V. Clathrin-Mediated Endocytosis of Quantum DotPeptide Conjugates in Living Cells. ACS Nano 2009, 3 (8), 24192429.

(39) Hua, S.; de Matos, M. B. C.; Metselaar, J. M.; Storm, G. Current Trends and Challenges in the Clinical Translation of Nanoparticulate Nanomedicines: Pathways for Translational Development and Commercialization. Front Pharmacol 2018, 9, 790.

(40) Ratajczak, J.; Joffraud, M.; Trammell, S. A. J.; Ras, R.; Canela, N.; Boutant, M.; Kulkarni, S. S.; Rodrigues, M.; Redpath, P.; Migaud, M. E.; Auwerx, J.; Yanes, O.; Brenner, C.; Canto, C. Nrk1 Controls Nicotinamide Mononucleotide and Nicotinamide Riboside Metabolism in Mammalian Cells. Nat. Commun. 2016, 7 (1), 13103.

(41) McReynolds, M. R.; Chellappa, K.; Baur, J. A. Age-Related NAD ${ }^{+}$ Decline. Exp. Gerontol. 2020, 134, 110888.

(42) Yoshino, J.; Baur, J. A.; Imai, S.-I. NAD ${ }^{+}$Intermediates: The Biology and Therapeutic Potential of Nmn and Nr. Cell Metab. 2018, 27 (3), 513-528.

(43) Cogger, V. C.; Hunt, N. J.; Le Couteur, D. G. Fenestrations in the Liver Sinusoidal Endothelial Cell. In The Liver: Biology and Pathobiology, 6th ed.; Arias, I. M., Alter, H. J., Boyer, J. L., Cohen, D. E., Shafritz, D. A., Thorgeirsson, S. S., Wolkoff, A. W., Eds.; WileyBlackwell: Hoboken, NJ, 2020; pp 435-443.

(44) Mohamad, M.; Mitchell, S. J.; Wu, L. E.; White, M. Y.; Cordwell, S. J.; Mach, J.; Solon-Biet, S. M.; Boyer, D.; Nines, D.; Das, A.; Catherine Li, S.-Y.; Warren, A.; Hilmer, S. N.; Fraser, R.; Sinclair, D. A.; Simpson, S. J.; Cabo, R.; Le Couteur, D. G.; Cogger, V. C. Ultrastructure of the Liver Microcirculation Influences Hepatic and Systemic Insulin Activity and Provides a Mechanism for Age-Related Insulin Resistance. Aging Cell 2016, 15 (4), 706-715.

(45) Fraser, J. A.; Kemp, S.; Young, L.; Ross, M.; Prach, M.; Hutchison, G. R.; Malone, E. Silver Nanoparticles Promote the Emergence of Heterogeneic Human Neutrophil Sub-Populations. Sci. Rep 2018, 8 (1), 7506-14.

(46) Friedman, S. L. Liver Fibrosis - From Bench to Bedside. J. Hepatol. 2003, 38, 38-53.

(47) Poynard, T.; Bedossa, P.; Opolon, P. Natural History of Liver Fibrosis Progression in Patients with Chronic Hepatitis C. Lancet 1997, 349 (9055), 825-832.

(48) Desmoulière, A.; Darby, I. A.; Gabbiani, G. Normal and Pathologic Soft Tissue Remodeling: Role of the Myofibroblast, with Special Emphasis on Liver and Kidney Fibrosis. Lab. Invest. 2003, 83 (12), $1689-1707$.

(49) Glancy, D.; Zhang, Y.; Wu, J. L. Y.; Ouyang, B.; Ohta, S.; Chan, W. C. W. Characterizing the Protein Corona of Sub-10 Nm Nanoparticles. J. Controlled Release 2019, 304, 102-110.

(50) Lundqvist, M.; Stigler, J.; Elia, G.; Lynch, I.; Cedervall, T.; Dawson, K. A. Nanoparticle Size and Surface Properties Determine the Protein Corona with Possible Implications for Biological Impacts. Proc. Natl. Acad. Sci. U. S. A. 2008, 105 (38), 14265-14270.

(51) Walkey, C. D.; Olsen, J. B.; Guo, H.; Emili, A.; Chan, W. C. W. Nanoparticle Size and Surface Chemistry Determine Serum Protein
Adsorption and Macrophage Uptake. J. Am. Chem. Soc. 2012, 134 (4) 2139-2147.

(52) Fischer, H. C.; Liu, L.; Pang, K. S.; Chan, W. C. W. Pharmacokinetics of Nanoscale Quantum Dots: InVivo Distribution, Sequestration, and Clearance in the Rat. Adv. Funct. Mater. 2006, 16 (10), 1299-1305.

(53) Poon, W.; Zhang, Y.-N.; Ouyang, B.; Kingston, B. R.; Wu, J. L. Y.; Wilhelm, S.; Chan, W. C. W. Elimination Pathways of Nanoparticles. ACS Nano 2019, 13 (5), 5785-5798.

(54) Loeschner, K.; Hadrup, N.; Qvortrup, K.; Larsen, A.; Gao, X.; Vogel, U.; Mortensen, A.; Lam, H. R.; Larsen, E. H. Distribution of Silver in Rats Following 28 Days of Repeated Oral Exposure to Silver Nanoparticles or Silver Acetate. Part. Fibre Toxicol. 2011, 8 (1), 18.

(55) Barzilai, N.; Crandall, J. P.; Kritchevsky, S. B.; Espeland, M. A. Metformin as a Tool to Target Aging. Cell Metab. 2016, 23 (6), 10601065.

(56) Knowler, W. C.; Barrett-Connor, E.; Fowler, S. E.; Hamman, R. F.; Lachin, J. M.; Walker, E. A.; Nathan, D. M. Reduction in the Incidence of Type 2 Diabetes with Lifestyle Intervention or Metformin. N. Engl. J. Med. 2002, 346 (6), 393-403.

(57) Schlender, L.; Martinez, Y. V.; Adeniji, C.; Reeves, D.; Faller, B.; Sommerauer, C.; Al Qur'an, T.; Woodham, A.; Kunnamo, I.; Sönnichsen, A.; Renom-Guiteras, A. Efficacy and Safety of Metformin in the Management of Type 2 Diabetes Mellitus in Older Adults: A Systematic Review for the Development of Recommendations to Reduce Potentially Inappropriate Prescribing. BMC Geriatr. 2017, 17 (S1), 227.

(58) Dujic, T.; Zhou, K.; Donnelly, L. A.; Tavendale, R.; Palmer, C. N. A.; Pearson, E. R. Association of Organic Cation Transporter 1 with Intolerance to Metformin in Type 2 Diabetes: A Godarts Study. Diabetes 2015, 64 (5), 1786-1793.

(59) McCreight, L. J.; Bailey, C. J.; Pearson, E. R. Metformin and the Gastrointestinal Tract. Diabetologia 2016, 59 (3), 426-435.

(60) Grozio, A.; Mills, K. F.; Yoshino, J.; Bruzzone, S.; Sociali, G.; Tokizane, K.; Lei, H. C.; Cunningham, R.; Sasaki, Y.; Migaud, M. E.; Imai, S.-I. Slc12a8 Is a Nicotinamide Mononucleotide Transporter. Nat. Metab 2019, 1 (1), 47-57.

(61) Poisson, J.; Lemoinne, S.; Boulanger, C.; Durand, F.; Moreau, R.; Valla, D.; Rautou, P.-E. Liver Sinusoidal Endothelial Cells: Physiology and Role in Liver Diseases. J. Hepatol. 2017, 66 (1), 212-227.

(62) Park, K. The Beginning of the End of the Nanomedicine Hype. J. Controlled Release 2019, 305, 221-222.

(63) Dai, Q.; Wilhelm, S.; Ding, D.; Syed, A. M.; Sindhwani, S.; Zhang, Y.; Chen, Y. Y.; MacMillan, P.; Chan, W. C. Quantifying the LigandCoated Nanoparticle Delivery to Cancer Cells in Solid Tumors. ACS Nano 2018, 12 (8), 8423-8435.

(64) Lammers, T.; Ferrari, M. The Success of Nanomedicine. Nano Today 2020, 31, 100853.

(65) Ortega-Ribera, M.; Hunt, N. J.; Gracia-Sancho, J.; Cogger, V. C. The Hepatic Sinusoid in Aging and Disease: Update and Advances from the 20th Liver Sinusoid Meeting. Hepatol Commun. 2020, 4 (7), 1087-1098.

(66) Wong, X. Y.; Sena-Torralba, A.; Álvarez-Diduk, R.; Muthoosamy, K.; Merkoçi, A. Nanomaterials for Nanotheranostics: Tuning Their Properties According to Disease Needs. ACS Nano 2020, 14 (3), $2585-2627$.

(67) Tang, R.; Xue, J.; Xu, B.; Shen, D.; Sudlow, G. P.; Achilefu, S. Tunable Ultrasmall Visible-to-Extended Near-Infrared Emitting Silver Sulfide Quantum Dots for Integrin-Targeted Cancer Imaging. ACS Nano 2015, 9 (1), 220-230.

(68) Cogger, V. C.; O’Reilly, J. N.; Warren, A.; Le Couteur, D. G. A Standardized Method for the Analysis of Liver Sinusoidal Endothelial Cells and Their Fenestrations by Scanning Electron Microscopy. JoVE 2015, No. 98, No. e52698.

(69) Kang, S. W. S.; Cogger, V. C.; Le Couteur, D. G.; Fu, D. Multiple Cellular Pathways Regulate Lipid Droplet Homeostasis for the Establishment of Polarity in Collagen Sandwich-Cultured Hepatocytes. Am. J. Physiol Cell Physiol 2019, 317 (5), C942-C952. 
(70) Warren, A.; Bertolino, P.; Cogger, V. C.; McLean, A. J.; Fraser, R.; Le Couteur, D. G. Hepatic Pseudocapillarization in Aged Mice. Exp. Gerontol. 2005, 40 (10), 807-812.

(71) Miller, D. L.; Yu, I. J.; Genter, M. B. Use of Autometallography in Studies of Nanosilver Distribution and Toxicity. Int. J. Toxicol. 2016, 35 (1), 47-51.

(72) Zhang, Y.; Hedo, R.; Rivera, A.; Rull, R.; Richardson, S.; Tu, X. M. Post Hoc Power Analysis: Is It an Informative and Meaningful Analysis? Gen Psychiatry 2019, 32 (4), No. e100069. 